\title{
Household Debt and Income Inequality, 1963-2003
}

\author{
Matteo Iacoviello* \\ Boston College
}

October 18, 2007

\begin{abstract}
I construct an economy with heterogeneous agents that mimics the time-series behavior of the earnings distribution in the United States from 1963 to 2003. Agents face aggregate and idiosyncratic shocks and accumulate real and financial assets. I estimate the shocks that drive the model using data on income inequality, aggregate income, and measures of financial liberalization. I show how the model economy can replicate two empirical facts: the trend and cyclical behavior of household debt, and the diverging patterns in consumption and wealth inequality over time. While business cycle fluctuations can account for the short-run changes in household debt, its prolonged rise of the 1980s and the 1990s can be quantitatively explained only by the concurrent increase in income inequality.

Keywords: Income Inequality, Household Debt, Credit Constraints, Incomplete Markets.

Jel Codes: D11, D31, D58, D91, E21, E44.
\end{abstract}

${ }^{*}$ Email: iacoviel@bc.edu. Address: Department of Economics, Boston College, Chestnut Hill, MA 02467-3806, USA. 
This paper uses a dynamic general equilibrium model with heterogeneous agents to study the trend and the cyclical properties of household debt in a unified framework. ${ }^{1}$ The approach is motivated by two empirical facts about the behavior of household debt, both illustrated in Figure 1. At long-run frequencies (top panel), the behavior of household debt closely mirrors earnings inequality: the cross-sectional standard deviation of log earnings was roughly constant between 1963 and 1980 and increased sharply in the period between 1981 and 2003. At the same time, gross household debt was relatively stable throughout the 1960s and the 1970s and since the 1980s has jumped out of proportion with real activity, rising between 1981 and 2003 from 66 percent to 113 percent of disposable personal income. ${ }^{2}$ At cyclical frequencies (bottom panel), household debt moves together with economic activity. For instance, the correlation between annual growth in disposable personal income and annual growth in household debt $^{3}$ equals 0.49 .

On the basis of this evidence, this paper asks the following question: can one construct a quantitative dynamic model that explains the trend and the cycle in household debt? The answer is yes. Two ingredients are crucial for this result. On the one hand, binding collateral constraints for a fraction of the population explain the cyclicality of household debt. On the other, time-varying cross-sectional dispersion in earnings goes a long way in explaining, qualitatively and quantitatively, the trend. According to the model, the cyclicality of debt primarily reflects the behavior of credit constrained agents, whose credit constraints get relaxed in good times, thus allowing them to borrow more. The trend rise in debt since the 1980s, instead, reflects the increased access of households to the credit market in order to smooth consumption in the face of more volatile incomes.

Explanations for the rise in household debt have referred to a combination of factors, including smaller business cycle fluctuations, the reduced costs of financial leveraging, changes in the regulatory environment for lenders and new technologies to control credit risk. To date, however, no study has tried to connect systematically micro and macro volatility with the behavior of household

\footnotetext{
${ }^{1}$ In this paper household debt refers to the gross outstanding debt of households. In the Flow of Funds accounts, household debt is constructed in a similar way, partly using microeconomic data, partly as a residual given data on financial assets owned by other sectors. In the model, I assume that all savings are frictionlessly intermediated by a perfectly competitive banking sector, so that debt is the sum of all households' financial liabilities. I consider a closed economy (so that net debt is zero) and do not allow for business or public or external debt.

${ }^{2}$ The increase in earnings inequality has been apparent in any data dimension (pre- and post-tax, between and within groups, along the permanent and transitory components). The earnings inequality series I use is constructed from Eckstein and Nagypál (2004) using data drawn from the March Current Population Survey and refers to the standard deviation of pre-tax log wages of full-time, full-year male workers. Measures of inequality constructed by other authors and based on different data sets or samples show the same pattern.

${ }^{3}$ Both series have been deflated using the implicit price deflator for personal consumption expenditures.
} 
debt. There are several reasons, however, to believe that both aggregate and idiosyncratic events affect the need of households to access the credit market. This is the perspective adopted here. At the aggregate level, macroeconomic developments should affect both the trend and the cyclical behavior of debt: over long horizons, as countries become richer, their financial systems better allocate the resources between those who have funds and those who need them. In addition, over the cycle, borrowers' balance sheets are strongly procyclical, thus causing credit to move in tandem with economic activity.

At the cross-sectional level, the arguments are different. Suppose that permanent income does not change, but the individual income patterns become more erratic over time, thus raising earnings dispersion at each point in time. Agents will try to close the gap between actual income (which determines current period resources) and permanent income (which affects consumption) by trading a larger amount of financial assets. When one aggregates these assets across the population, market clearing implies that they sum to zero, but their dispersion increases. As a consequence, aggregate debt - the sum of all the negative financial positions - rises when income dispersion is greater.

The stories above lead to the main question of the paper: how do the shocks to aggregate income and to its distribution affect the behavior of credit flows? I address this issue by constructing a model of the interaction between income volatility, household-sector financial balances, and the distribution of expenditure and wealth. Households receive an exogenous income, consume durable and non-durable goods, and trade a riskless asset in order to smooth utility. An exogenous fraction of households is assumed to have unrestricted access to the credit market, which they use in order to smooth expenditure in the face of a time-varying income profile. The remaining households are assumed to be impatient and credit constrained, in that they can only borrow up to a fraction of their collateral holdings. At each point in time, the economy features variables that move in line with macroeconomic aggregates. At the same time, time-varying volatility in the idiosyncratic income shocks alters the distribution of income, and therefore of consumption, wealth, and financial assets. Because my main goal is to understand the behavior of household debt, I use the model to conduct the following experiment: I use data on income inequality to back out stochastic processes for the idiosyncratic income shocks that allow replicating income inequality over time. I use data on loan-to-value ratios and aggregate income to estimate processes for "financial" shocks and aggregate income shocks. I then consider the role of each of these factors in explaining the patterns in the data, in particular, the trend and the cyclical behavior of household debt and the distribution of consumption and wealth across the population. The key finding of the paper lies in the model's ability to explain three salient features of the data: 
1. The model explains the timing and the magnitude of the rise in household debt over income and attributes its increase to the concurrent rise in income inequality.

2. The model can reconcile the sharp increase in income inequality over the period 1981-2003 with a smaller rise in consumption inequality, and a larger increase in wealth inequality.

3. The model captures well the cyclical behavior of household debt.

Because my main goal is to study the dynamics of the economy between 1963 and 2003, I assume that, in 1963, the economy is in a steady state that exactly matches household debt and other key macroeconomic variables. I then solve the model by linearizing around such a steady state the equations describing the equilibrium and feed the model with shocks estimated from the actual data. From the computational point of view, this technique has the advantage that, even when dealing with a large number of agents, the equilibrium decision rules keep track of all the moments of the wealth distribution. In addition, one does not need to restrict the stochastic components of the model to a low dimensional discrete state process, and one can describe very accurately the evolution of the variables over time. The linearization, of course, neglects the effects of risk on optimal decisions and ignores constraints on the asset position that are occasionally binding: risk considerations would call for higher order pertubation methods; occasionally binding constraints and large shocks, however, would rule out perturbation methods in favor of global approximation schemes. To address these issues, in the concluding part of the paper I study the transitional dynamics of a bare-bones version of the model that can be conveniently solved using value (and policy) function iteration and guessing a finite time path for prices during the transition. ${ }^{4} \mathrm{I}$ then show that the results from the linear and the non-linear method are very close. The intuition is simple, given the nature of the problem that the agents in the model face: the policy functions of non-linear model are essentially linear in the region of state space where patient and impatient agents spend their time; borrowing of the unconstrained agents depend negatively (as well as linearly) in the amount of cash-on-hand; borrowing of the constrained agents depends positively (and linearly) in the amount of cash-on-hand in the region where these agents spend most of their time. I then characterize the transitional dynamics of the model when the only "aggregate" shock is a one-time change in earnings dispersion that mimics the average increase in inequality of the

\footnotetext{
${ }^{4}$ Den Haan (1997), Krusell and Smith (1998) and Ríos-Rull (1999) have proposed methods to solve incomplete market models with a large number of agents and idiosyncratic and aggregate shocks that do not rely upon linearizations. These methods are computationally too burdensome to be adapted to a model with several state variables and shocks drawn from a continuous support.
} 
1980s and the 1990s. As the results show, the predictions of the non-linear model are very close to those of the linearized model: the amount of debt is higher when inequality is higher; impatient agents are always at their borrowing ceiling; and patient agents smooth their consumption very effectively and almost never hit the upper bound on their debt.

Section 1 briefly reviews the facts. Section 2 presents the model. Section 3 describes the calibration and the simulation of the model. Section 4 presents the results. Section 5 contains robustness analysis. Section 6 discusses the transitional dynamics of the nonlinear model. Section 7 concludes.

\section{Debt and Inequality in the United States}

Household Debt. The top panel of Figure 1 plots household debt over disposable personal income from 1963 to 2003. The ratio of debt to income was relatively stable throughout the 1960s and the 1970s, which led some economists to suggest that monetary policy should target broad credit aggregates in place of monetary aggregates. Debt to income expanded at a fast pace from the mid 1980s on, fell slightly in the 1990-1991 recession, and began a gradual increase from 1994 on. At the end of 2003, the ratio of household debt to disposable personal income was 113 percent. The increase in debt has been accompanied by a gradual rise over time of commonly used measures of financial sector imbalances. For instance, the household debt service ratio (an estimate of the ratio of debt payments to disposable personal income) rose from 0.106 in 1983 to 0.132 in 2003. The increase in household debt has been common to both home mortgage debt and consumer debt, although it has been more pronounced for the former. Consumer debt averaged around 20 percent of disposable personal income in the early period and rose to about 25 percent in the later period. Mortgage debt (which includes home equity lines of credit and home equity loans) to disposable personal income averaged around 40 percent in the 1960-1980 period and rose to about 75 percent in the late 1990s. ${ }^{5}$

Inequality. Several papers have documented upward trends in income and earnings inequality in the United States (see Katz and Autor, 1999, Moffitt and Gottschalk, 2002, Piketty and Saez, 2003, Eckstein and Nagypál, 2004, Krueger and Perri, 2006, and Lemieux, 2006). As shown in the top panel of Figure 1, inequality was little changed in the 1960s, increased slowly in the 1970s and sharply in the early 1980s, and has continued to rise, at a slightly slower pace, since

\footnotetext{
${ }^{5}$ Consistent data on home equity loans go back only to the 1990s. According to these data, home equity loans rose from 5 to 8 percent of disposable income between 1991 and 2003.
} 
the 1990s. Looking across studies and data sets, inequality (measured by the standard deviation of log earnings) appears to have increased by about $15 \log$ points between the beginning of the 1980s and the late 1990s. The magnitude of the increase is fairly similar across different data sets (Consumer Expenditure Survey, Panel Study of Income Dynamics and Current Population Survey) and definitions of income (pre-tax wages, post-tax wages and total earnings). ${ }^{6}$

Against the backdrop of rising income inequality, consumption inequality has risen by a smaller amount. For instance, Krueger and Perri (2006) find that the standard deviation of log consumption rose by about 7 log points (half as much as that of income) between 1980 and 2003.

\section{The Model}

The Environment. My model is a simplified version of the Krusell and Smith (1998) framework in which the stochastic growth model is modified to account for individual heterogeneity. Time is discrete. The economy consists of a large number of infinitely-lived agents who are distinguished by the scale of their income, by their discount rates, and by their access to the credit market. Agents are indexed by $i$. Each agent receives a stochastic income endowment and accumulates financial assets and real assets (a house) over time. ${ }^{7}$

The credit market works as follows. A fraction of the agents (unconstrained, patient agents) can freely trade one-period consumption loans, subject to a no-Ponzi-game condition. The remaining agents (constrained, impatient agents) cannot commit to repay their loans and need to post collateral to secure access to the credit market. By contrast, unbacked claims are enforceable among patient agents, whose credit limits are so large that they never bind. For all agents, the amounts they are allowed to borrow can be repaid with probability one, and there is no default.

On the income side, agents differ in the scale of their total endowment, which, absent shocks, can be thought as the source of permanent inequality in the economy. Earnings differentials across agents are exogenous. ${ }^{8}$ For each agent, the log earning process is the sum of three components: (1)

\footnotetext{
${ }^{6}$ Besides Figure 1 in this paper, see, for instance, Figure 2b in the appendix of Lemieux (2005), for hourly pre-tax wages using the CPS as well as the May and Outgoing Rotation Group supplements of the CPS; Figure 1 in Krueger and Perri (2006), for labor income after taxes and transfers using Consumer Expenditure Survey data; and Figure 1 in Heathcote, Storesletten and Violante (2004), using PSID data.

${ }^{7}$ Unlike Krusell and Smith (1998), my main focus is on endogenous borrowing constraints and on the distribution of financial assets across households. For this reason, I abstract from capital accumulation and from endogenous labor supply.

${ }^{8}$ In the model, I refer to income and earnings inequality interchangeably excluding any gain/loss from interest payments from the income/earnings definition.
} 
an individual-specific fixed effect; (2) a time-varying aggregate component; and (3) a time-varying individual component.

Patient Agents. A fraction $\frac{n}{N}$ of agents have a low discount rate and do not face borrowing constraints (other than a no-Ponzi-game condition). Each of them maximizes a lifetime utility function over consumption and durables (housing) given by:

$$
\max E_{0} \sum_{t=0}^{\infty} \beta^{t}\left(\log c_{i t}+j \log h_{i t}\right)
$$

where $i=\{1,2,3, \ldots, n\}$, where $c$ is consumption, and $h$ denotes holdings of durables (whose services are assumed to be proportional to the stock). The flow of wealth constraint is:

$$
c_{i t}+h_{i t}-(1-\delta) h_{i t-1}+R_{t-1} b_{i t-1}=y_{i t}+b_{i t}-\phi\left(b_{i t}-b_{i}\right)^{2}
$$

where $b_{i}$ denotes debt (so that $-b_{i}$ denotes financial assets) of agent $i, R$ is the gross interest rate, and $y_{i}$ is the household income. The last term represents an arbitrarily small quadratic cost of holding a quantity of debt different from $b_{i}$ (that will be the steady state debt for agent $i$ ). This cost allows pinning down steady state financial positions of each agent in this group, but has no effect on the dynamics of the model. ${ }^{9}$ For each agent, the first order conditions involve standard Euler equations for consumption and durables as follows: ${ }^{10}$

$$
\begin{gathered}
\frac{1}{c_{i t}}-2 \phi\left(b_{i t}-b_{i}\right)=E_{t}\left(\frac{\beta}{c_{i t+1}} R_{t}\right) \\
\frac{1}{c_{i t}}=\frac{j}{h_{i t}}+\beta E_{t}\left(\frac{1-\delta}{c_{i t+1}}\right) .
\end{gathered}
$$

Impatient Agents. A fraction $\frac{N-n}{N}$ of agents discount the future more heavily ${ }^{11}$ and face a collateral constraint that limits the amount of borrowing to a time-varying fraction of their durables.

\footnotetext{
${ }^{9}$ Throughout the paper, I abstract from aggregate growth. Starting from the data, I detrend log real income using a bandpass filter that isolates the frequencies between 1 and 8 years; the same trend in income is used to detrend real debt, so that the ratio of detrended real debt to detrended real GDP is identical to the ratio of the non-filtered series. One could easily incorporate growth in the model. For example, one could assume a deterministic trend in aggregate income and then define a transformed, stationary economy with slightly altered discount factors and a slight modification of the budget constraints. This economy would then have the same properties of the non-transformed economy without growth. See, for instance, the discussion in Aiyagari (1994).

${ }^{10}$ The no-Ponzi-game constraint is $\lim _{j \rightarrow \infty} E_{t} \frac{b_{i t+j}}{\prod_{s=0}^{j} R_{t+s}} \leq 0$.

${ }^{11}$ Impatience is a convenient modeling device to obtain an equilibrium in which some agents are credit constrained. Several studies (see, for instance, the references cited in Frederick, Loewenstein, and O'Donoghue, 2002) have found large empirical support for discount rate heterogeneity across the population.
} 
With this assumption, I want to capture the idea that, for some agents, enforcement problems are such that only real assets can be used as a form of collateral. The problem they solve is:

$$
\max E_{0} \sum_{t=0}^{\infty} \gamma^{t}\left(\log c_{i t}+j \log h_{i t}\right)
$$

where $i=\{n+1, n+2, \ldots, N\}$, where $\gamma<\beta$, subject to the following budget constraint:

$$
c_{i t}+h_{i t}-(1-\delta) h_{i t-1}+R_{t-1} b_{i t-1}=y_{i t}+b_{i t}
$$

and to the following borrowing constraint:

$$
b_{i t} \leq m_{t} h_{i t}
$$

For each unit of $h$ they own, impatient agents can borrow at most $m_{t}$ : exogenous time variation in $m$ proxies for any shock to the economy-wide supply of credit that is independent of income, as in Ludvigson (1999). The first order conditions can be written as:

$$
\begin{aligned}
\frac{1}{c_{i t}} & =E_{t}\left(\frac{\gamma}{c_{i t+1}} R_{t}\right)+\lambda_{i t} \\
\frac{1}{c_{i t}} & =\frac{j}{h_{i t}}+\gamma E_{t}\left(\frac{1-\delta}{c_{i t+1}}\right)+m_{t} \lambda_{i t} .
\end{aligned}
$$

These conditions are thus isomorphic to those of patient agents, with the crucial addition of $\lambda_{i t}$, the Lagrange multiplier on the borrowing constraint. It is straightforward to show that, around the non-stochastic steady state, the low discount factor will push impatient agents toward the borrowing constraint. In other words, as long as $\gamma<\beta$, the multiplier $\lambda$ on the borrowing constraint will be strictly positive. ${ }^{12}$ As a consequence, the patient agents' behavior will determine the interest rate on the entire equilibrium path. ${ }^{13}$

Equilibrium. A stationary recursive competitive equilibrium is a set of stationary stochastic processes $\left\{\mathbf{h}_{t}, \mathbf{c}_{t}, \mathbf{b}_{t}, R_{t}\right\}_{t=0}^{\infty}$ for the endogenous variables, where $\mathbf{h}_{t}=\left\{h_{1 t}, \ldots, h_{N t}\right\}, \mathbf{c}_{t}=$ $\left\{c_{1 t}, \ldots, c_{N t}\right\}$, and $\mathbf{b}_{t}=\left\{b_{1 t}, \ldots, b_{N t}\right\}$ are vectors collecting the individual variables, satisfying Euler equations, budget and borrowing constraints, and the following market clearing condition:

$$
\sum_{i=1}^{N}\left(c_{i t}+\left(h_{i t}-(1-\delta) h_{i t-1}\right)\right)+\sum_{i=1}^{n} \phi\left(b_{i t}-b_{i}\right)^{2}=\sum_{i=1}^{N} y_{i t} \equiv Y_{t}
$$

\footnotetext{
${ }^{12}$ To obtain this result, the impatience motive must be sufficiently strong. The result also holds in the stationary equilibrium and in the transition of the non-linear model solved in Section 6.

${ }^{13}$ Krusell, Kuruşçu and Smith (2001) illustrate a similar point in a model with quasi-geometric discounting and heterogeneity in preferences. See also Iacoviello (2005) for a related application and for a discussion in the context of a monetary business cycle model with heterogeneous agents.
} 
given the processes for $\mathbf{y}_{t}=\left\{y_{1 t}, \ldots, y_{N t}\right\}$ and $m_{t}$ and the initial conditions $\left\{\mathbf{h}_{t-1}, \mathbf{b}_{t-1}, R_{t-1}\right\}$.

Operationally, I find the (certainty-equivalent) laws of motion of the model by linearizing around the steady state the set of equations describing the equilibrium and using the method of undetermined coefficients. ${ }^{14}$ If the number of agents in the model is $N$, the linearized model features $4 N+3$ equations. For each agent, there are a flow of funds constraint, two Euler equations, and an income process equation. The remaining three equations are, respectively, the market clearing condition (which determines the interest rate) and the processes for aggregate income and for the loan-to-value. I set $N=500$ in my computations. ${ }^{15}$

Dynamics. To study the dynamics of the economy, I consider the following experiment. I assume that, before 1963, the economy is at its non-stochastic steady state. There are then unexpected shocks to aggregate income, to the loan-to-value ratio, and to individual incomes. These shocks are constructed from actual data so that their sequence matches the behavior of aggregate earnings, loan-to-values, and earnings inequality. For each individual, income evolves according to

$$
y_{i t}=f_{i} a_{t} z_{i t}
$$

where $f_{i}$ is an individual specific fixed effect; $a_{t}$ denotes an aggregate component; and $z_{i t}$ denotes an idiosyncratic component. The aggregate and idiosyncratic components obey the following autoregressive representations: ${ }^{16}$

$$
\begin{aligned}
\log a_{t} & =\rho_{a} \log a_{t-1}+e_{a t} \\
\log z_{i t} & =\rho_{z} \log z_{i t-1}+e_{i t}
\end{aligned}
$$

where $e_{a}$ is normally distributed with zero mean and constant variance, whereas $e_{i t} \sim N\left(-x_{t}, v_{t}^{2}\right)$. The variable $e_{i t}$ is independently distributed across agents but not over time: that is, the variance of

\footnotetext{
${ }^{14}$ To achieve a good approximation, I log-linearize the variables that are linear in logs, like individual income. I also use log-linearization for consumption and housing, and for the debt of constrained agents, which is always positive along the equilibrium path. Because financial assets of the unconstrained agents can take on negative as well as positive values, I linearize (instead of log-linearizing) this variable.

${ }^{15}$ For the idiosyncratic shocks to wash out in the aggregate, one would like to set $N$ to an arbitrarily large number, so that the law of large numbers holds. I ensure that the idiosyncratic shocks do not have aggregate effects by centering them appropriately. See Appendix A for more details. The model predictions were virtually identical for $N=200$ and for $N=500$, so I concluded that setting $N=500$ as opposed to a larger number does not materially affect the results of the simulations.

${ }^{16}$ Once the vector of shocks is realized in each period $t$, agents form expectations on the paths of the exogenous variables according to their laws of motion and forecast future quantities and prices on the basis of all available information at time $t$.
} 
the individual income shocks is allowed to be time-varying. By virtue of the law of large numbers, these shocks affect only the distribution of income but not its mean level. (See Appendix B for more on this. Because the variance of the shocks is time varying, one needs to correct the cross-sectional mean of $e_{i t}$ so that the mean level of income remains constant over time; otherwise aggregate income would be high in periods of high idiosyncratic variance.) Finally, the loan-to-value ratio follows:

$$
m_{t}=\left(1-\rho_{m}\right) m_{s s}+\rho_{m} m_{t-1}+e_{m t}
$$

where $m_{s s}$ is the steady state value of $m$, and $e_{m t} \sim N\left(0, \sigma_{m}^{2}\right)$.

\section{Calibration and Simulation}

Overview. To check whether the model can account for the main stylized facts in the data, I use the following procedure:

1. In the initial steady state, I set $\log a_{t}=0$ and $\log z_{i t}=0$ for all $i$ 's. I set the fixed effects in the income process (the distribution of $f_{i}$ ) to match the 1963 standard deviation of $\log$ incomes.

2. I calibrate the model, so that the initial steady state matches key observations of the US economy in 1963. In detail, I set the parameters describing preferences and technology $(\beta, \gamma, \delta, j)$ so that in the initial steady state the ratio of durable wealth to income and the interest rate match the data.

3. Once I choose a steady state value for the loan-to-value $m_{s s}$, the model endogenously generates aggregate debt holdings for the constrained agents. Next, I choose the $b_{i}$ 's in the bond holding cost function for the unconstrained agents so that the aggregate bond market clears:

$$
\sum_{i=1}^{N} b_{i}=0
$$

and the gross household debt matches the data in the initial steady state, where gross debt is defined as:

$$
D_{t}=\sum_{i=1}^{N}\left(b_{i t} \mid b_{i t}>0\right) .
$$

In 1963, the ratio of household debt to disposable personal income was 0.66 . Hence, I choose a distribution of $b_{i}$ 's across the unconstrained agents in a way that:

$$
\underset{\text { debt held by unconstrained agents }}{\sum_{i=1}^{n} b_{i}\left(b_{i} \mid b_{i}>0\right)}+\sum_{\text {debt held by constrained agents }}^{\sum_{i=n+1}} b_{i}=0.66 \sum_{\text {total income }}^{N} y_{i} .
$$


4. From the data, I construct sequences of aggregate income shocks, financial shocks (time variation in the loan-to-value ratio $m_{t}$ ), and idiosyncratic income shocks (time variation in the cross-sectional earnings dispersion). I then feed the estimated shocks into the model's linearized decision rules starting from 1963, and I check whether the time series generated from the model can replicate the behavior of debt, consumption inequality, and wealth inequality which are observed in the data.

Calibration. The time period is one year. This reflects the lack of higher frequency measures of income inequality, which are needed to construct the processes for idiosyncratic shocks. Table 1 summarizes the calibration. As explained above, the parameter choices are meant to capture the initial steady state distribution of income and financial assets, as well as the ratio of durable wealth to output.

Given that patient agents are unconstrained in steady state, I set their discount factor to 0.965 : this pins down the real interest rate at 3.5 percent per year. The durable/housing preferences weight $j$ is chosen to match the steady state ratio of household real estate wealth over income. A choice of $j=0.117$ (together with $\delta=0.04$ ) implies that this ratio is 1.39 , like its data counterpart ${ }^{17}$ in 1963. Together with the housing depreciation rate, this ensures that steady state residential investment is about 5.5 percent of income. The discount factor for impatient agents is set at 0.865. This number is in the ballpark of the estimates of Lawrence (1991), Samwick (1998) and Warner and Pleeter (2001). ${ }^{18}$ Although it does not have big effects on the dynamics, it guarantees that the impatience motive for this group is large enough that, even in the presence of large income shocks, they are almost surely borrowing constrained. The fixed effects in the earnings process are chosen so that the cross-sectional standard deviation of log earnings is 0.5173 in the initial steady state.

The share of unconstrained agents is set to 65 percent, a value in the range of estimates in the literature. Using aggregate data, Campbell and Mankiw (1989) estimate a fraction of rule-ofthumb/constrained consumers of around 40 percent. Using the 1983 Survey of Consumer Finances, Jappelli (1990) estimates 20 percent of the population to be liquidity constrained. Iacoviello (2005) finds that a share of constrained consumers of 34 percent helps to explain the positive response of aggregate spending to a housing price shock. I then pick the loan-to-value ratios. In 1963, the

\footnotetext{
${ }^{17}$ See Table B.100 of the Flow of Funds accounts, Z.1 release.

${ }^{18}$ Lawrence (1991) uses data from the Panel Study of Income Dynamics to estimate discount rates ranging from 12 to 19 percent. Samwick (1998) uses an OLG model and data from the Survey of Consumer Finances and finds discount rates ranging between -15 and 20 percent. Warner and Pleeter (2001) use evidence from military downsizing programs to estimate personal discount rates ranging between 0 and 30 percent.
} 
average loan-to-value ratio for new home purchases was 0.729 . Setting the initial value of $m$ to this number generates a ratio of debt held by constrained agents to total output of 31 percent.

As outlined above, the distribution of financial assets across unconstrained agents is chosen to match the 1963 value of household debt to income of 0.66. I first split unconstrained agents (65 percent of the population) into creditors and debtors, and assume that creditors are 35 percent of the total (and claim 66 percent of the total debt) and debtors are 30 percent of the total (and own, as a group, 35 percent of debt, that is, total debt less debt owned by constrained agents). This is roughly in line with data from the Survey of Consumer Finances (SCF), which indicate that a small fraction of the population has positive net financial assets. ${ }^{19}$ Next, I assume that financial assets (for the creditors) and liabilities (for the unconstrained debtors) are both log-normally distributed with the same standard deviation as that of log incomes. This way, the overall wealth distribution is more skewed than the income distribution, as in the data. Once the distributions are created, I have to decide the joint probability distribution of income and net financial assets for the unconstrained agents. The 1998 SCF documents a strong positive correlation between incomes and net financial assets, mainly driven by the large positive correlation between income and net financial assets at the top end of the income distribution. ${ }^{20}$ However, analogous data from the 1983 SCF show an opposite pattern, showing a negative correlation. ${ }^{21}$ The 1962 survey (the only survey conducted before 1983) is less detailed and harder to interpret, because the data classifications exclude mortgage debt from the financial liabilities. Because of this conflicting evidence, I assume that the net financial position of all unconstrained agents is uncorrelated with their initial income, but I report the results using alternative assumptions in Section 5. The left panel of Figure 2 is a scatter plot of the joint crosssectional distribution of income and debt in the 1963 steady state. Finally, the bond adjustment cost $\phi$ is set equal to 0.0001 . This number is small enough that it has no effect on the dynamics, but it ensures that, even when the economy is solved using linear methods, the individual bond positions are mean-reverting and the long-run value of household debt is equal to the initial value.

In the initial steady state, impatient agents have lower consumption-earnings and housingearnings ratios. This is due both to their low discount rates, which induce them to accumulate less wealth, and to their steady state debt burden, which reduces their current period resources. The

\footnotetext{
${ }^{19}$ I construct net financial assets from the SCF data as the difference between positive financial assets (like stocks, bonds, and checking accounts) and financial debts (like mortgages, car loans and credit card debt). Because my model does not differentiate among financial assets, it is plausible to look at this variable in the data as the counterpart to net financial assets (that is, minus $b$ ) in my model.

${ }^{20}$ See Aizcorbe, Kennickell and Moore (2003).

${ }^{21}$ See Kennickell and Shack-Marquez (1992).
} 
average propensities to consume for constrained and unconstrained agents are, respectively, 0.92 and 0.96; the average holdings of housing over income are, respectively, 1.15 and 1.53.

Recovering the Stochastic Processes for the Shocks. I extract the income shock from the log real disposable personal income series (see Appendix A for more details on the data). First, I use a bandpass filter that isolates frequencies between 1 and 8 years to remove the trend component. The resulting series is then modeled as an $A R(1)$ process and used to construct the $\log \left(a_{t}\right)$ process. The series has the following properties:

$$
\log a_{t}=0.54 \log a_{t-1}+e_{a t}, \sigma_{e a}=0.024
$$

and is positively correlated with the usual business cycle indicators; in particular, it shows declines in the periods associated with NBER-dated recessions. The top panel of Figure 3 plots the implied time series for the shock processes normalized to zero in 1963.

It is hard to construct a single indicator of the tightness of borrowing constraints, as measured by $m_{t}$. Financial liberalization has been a combination of a variety of factors that no single indicator can easily capture. Because it comes closest to proxying for the model counterpart, I use the loanto-price ratio on conventional mortgages for newly-built homes to construct the financial shocks. This way, I can construct a measure of time-varying liquidity constraints, which gives me the process for $m_{t} \cdot{ }^{22}$ As shown in the bottom panel of Figure 3, loan-to-value ratios have increased by a small amount over the sample relative to the 1963 baseline (which was 0.729 ), rising by about 5 percent. A sharp increase occurred in the early 1980s, when the Monetary Control Act of 1980 and the Garn-St. Germain Act of 1982 expanded households' options in mortgage markets, thus relaxing collateral constraints. The resulting series for the financial shock is (omitting the constant term):

$$
m_{t}=0.84 m_{t-1}+e_{m t}, \sigma_{e m}=0.011 .
$$

The series for $m$ (normalized to 0 in the base year) is plotted in the bottom panel of Figure 3 . The series displays a slight upward trend over time, which was not stastically significant. ${ }^{23}$ Of course, it is possible that this crude measure of financial liberalization does not capture in a comprehensive way the many possible ways in which the financial reforms of the 1980's and the 1990's might have

\footnotetext{
${ }^{22}$ Other measures of financial innovation, such as the homeowner's share of equity in her home, the percent of loans made with small down payments, or measures of credit availability from the Fed's Senior Loan Officer Opinion Survey, suffer from two main problems. First, they are more likely to suffer from endogeneity problems. Second, they suffer from a scaling problem: while they are likely to be good qualitative indicators of credit availability, they are harder to map into a quantitative indicator that can be fed into a model.

${ }^{23}$ I tested for the significance of a trend coefficient in the process for the LTV ratio. Repeating this regression
} 
improved access to credit for househols, thus biasing downward the contribution of financial reforms to the rise of household debt.

Finally, Appendix B describes how I use the observed measures of time-varying income inequality (measured by the cross-sectional variance of log incomes) to recover the idiosyncratic shocks that are consistent with given variations in income inequality, once assumptions are made about the persistence of the individual income process. Here I summarize my procedure. In the initial non-stochastic steady state, income dispersion is given by the variance of the log fixed effects, $\operatorname{var}\left(\log f_{i}\right)$. Over time, given the formula for the individual income processes, the cross-sectional log income dispersion evolves according to:

$$
\operatorname{var}\left(\log y_{t}\right)=\rho_{z}^{2} \operatorname{var}\left(\log y_{t-1}\right)+\left(1-\rho_{z}^{2}\right) \operatorname{var}\left(\log f_{i}\right)+v_{t}^{2}
$$

that is, observed income dispersion comes partly from the past, partly from new innovations. Given assumptions about $\rho_{z}$, one can use the time-series data on $\operatorname{var}\left(\log y_{t}\right)$ to construct recursively the time series of the cross-sectional variance $v_{t}^{2}$ of the individual shocks. Given the vector $v_{t}^{2}$, one can then draw from a normal distribution, in each period $t$, an $N \times 1$ vector of the individual innovations having a standard deviation equal to $v_{t}$.

A crucial parameter determining the behavior of the model is $\rho_{z}$, the autocorrelation in the individual income process. Heaton and Lucas (1996) allow for permanent but unobservable householdspecific effects and find a value of $\rho_{z}=0.53$ using the Panel Study of Income Dynamics. Storesletten, Telmer, and Yaron (2004) estimate a much higher value of $\rho_{z}=0.95$, although their estimates are based on the assumption of a slightly different income process. I take a value in between these numbers and choose $\rho_{z}=0.75$. In Section 5 , I document the robustness of my results to various alternative values of $\rho_{z}$.

Given observations on $\operatorname{var}\left(\log y_{t}\right)$ and for a given choice of $\rho_{z}$, I construct time series for the individual income processes that allow replicating the behavior of income dispersion over time. Because of the sampling uncertainty associated with each draw of idiosyncratic shocks, I report in the next sections data on the median result across 500 replications, and, when applicable, I plot in the figures the 10th and 90th percentile for the simulated model statistics.

\section{Some Caveats.}

including a time trend yields:

$$
m_{t}=0.67 m_{t-1}+0.00041 t+e_{m t} .
$$

The coefficient on the trend variable is positive, but the t-statistic is only 1.83 (with a p-value of 0.08 ), hence the null hypothesis of no trend cannot be rejected using conventional significance levels. 
1. Total inequality (income variance) is the sum of temporary inequality (due to shocks) and permanent inequality (due to fixed effects), if shocks are uncorrelated with the fixed effect. In the initial steady state, all of the dispersion in earnings is due to the fixed effect. With inequality growing over time, I can almost in every period back out the sequences of i.i.d. shocks $\left\{e_{i t}\right\}$ with variance $v_{t}^{2}$ that solve equation (8) given the observed behavior of $\operatorname{var}\left(\log y_{t}\right) .^{24}$

2. An implicit assumption of the model is that, at the individual level, starting from 1963, individuals face a sequence of income shocks whose variance is increasing over time. Because linearization implies that the optimal decision rules of the agents are linear in the state of the economy (which includes the shocks themselves), this allows characterizing the dynamics of the model even in the presence of time-varying volatility.

\section{Comparing the Model to the Data: 1963-2003}

Model Behavior. At the individual level, idiosyncratic shocks account for a large portion of income volatility. In response to positive income innovations, unconstrained agents behave like permanent income consumers, increasing expenditure by a small amount and reducing their debt. Instead, constrained agents behave like hand-to-mouth consumers and use the extra income to acquire more durables, to borrow more, and to spend more. To illustrate this point, Figure 4 plots typical income, consumption, and debt profiles over the simulation period for constrained and unconstrained agents. Across agents, the average correlation between debt and income level is -0.28 for the unconstrained agents, 0.95 for the constrained ones.

Table 2 reports some summary statistics. As shown in Figure 5, aggregate non-durable consumption is smoother than aggregate output, reflecting the fact that expenditure on durables is relatively more volatile. Interest rates move little, since they reflect the smooth consumption profile of unconstrained agents. As in many incomplete market models, individual consumption is more volatile than aggregate consumption. The standard deviation of consumption growth for the typical unconstrained agent is twice as large as that of aggregate consumption growth; for constrained agents, the corresponding ratio is about 12, thus suggesting that self-insurance does not work well for this group. Across all groups, the standard deviation of the individual consumption growth rate is about 0.08. This amount of consumption volatility is much higher than what a complete markets model would predict. Using the Consumption Expenditure Survey data, Brav, Constantinides, and

\footnotetext{
${ }^{24}$ I use the word almost because the assumption of no correlation between shocks and fixed effects places a lower bound on the value of inequality that can be matched by the data. For this reason, the model cannot fit exactly inequality in the 1970s, when earnings dispersion temporarily declined.
} 
Geczy (2002) find that the standard deviation of quarterly consumption growth is about 0.0633 for households with positive assets. If quarterly consumption growth is i.i.d., this corresponds to a standard deviation of annual consumption growth of 0.127 .

Aside from these individual stories, there is one important consequence of the aggregate implications of varying cross-sectional income dispersion. In the plots of Figure 4, one can notice how the individual income patterns become more erratic from the 1980s onward, reflecting the model parameterization that captures the rising earnings inequality in the data. Because consumption of the unconstrained agents will move much less than earnings, the increased dispersion of earnings will lead to a larger dispersion of financial assets. ${ }^{25}$

\section{Main Findings.}

1. The model successfully captures the trend behavior of debt over income.

In the data, the household debt-to-income ratio rises from 66 percent in 1963 to 113 percent in 2003. Figure 6 compares the model with the data. The figure shows that the equilibrium path from the model mirrors very closely the actual path of the data. As in the data, the model predicts, starting from the 1963 steady state, flat household debt-to-income ratios until the mid-1980s, and a sharp increase from the mid-1980s on. The increase is more pronounced in periods in which inequality rises very fast, and lags inequality slightly.

2. The model roughly captures the cyclical behavior of debt.

Figure 7 compares year-on-year debt growth in the model and in the data. The correlation between the two series is clearly positive (its average value is 0.46 ) and different from zero at conventional significance levels. In the earlier period, the model captures well the comovement between the two series, although the volatility of debt growth is smaller than in the data. In the later period, the cyclical variation of the model series is similar to the data, although the model slightly overpredicts debt growth in the 1980s and underpredicts debt growth in the 1990s and later.

3. The model predicts a small rise of consumption inequality and a large rise in wealth inequality, as in the data.

Figure 8 plots simulated time profiles for income inequality, non-durable consumption inequality and wealth inequality. Because wealth can take on negative values, I plot the Gini

\footnotetext{
${ }^{25}$ The right panel of Figure 2 plots the 2003 income and debt positions of all agents in a typical simulation.
} 
index for all three variables. While the Gini index for income rises by 0.10 units over the sample period, the increase in the Gini index for consumption is only half as much. Krueger and Perri (2006) document these facts ${ }^{26}$ in the data and obtain a similar result in a model of endogenous developments in credit markets. The increase in wealth inequality is much larger. ${ }^{27}$ This is explained by the fact that rich people in the model accumulate positive financial assets over time. ${ }^{28}$

\section{The model attributes the trend increase in debt to the rise in inequality.}

A closer look at the sources of shocks in the model highlights the role of income inequality as the leading cause of the increase in debt over income from 1984 on.

To disentangle the relative contribution of each of the shocks in explaining the time-series behavior of household debt, Figures 9 and 10 show the historical decomposition of the debt/income ratio and of debt growth in the model in terms of the three model shocks. ${ }^{29}$ Figure 9 shows that the behavior of income inequality accounts for the trend variation in debt. Had income inequality not changed from its baseline value, the debt-to-income ratio would not have increased. Financial shocks account for about 5 percent of the increase in debt over income. And cyclical variations in productivity, by their own nature, should not have affected long-run trends in debt. Figure 10 illustrates that income and financial shocks seem to account well for the positive correlation between debt growth in the model and the data counterpart, although financial shocks alone seem unable to capture cyclical movements in debt growth.

To conclude, given the calibrated income processes, the model captures the cyclical and trend dynamics of debt on the one hand, and consumption and wealth inequality on the other. This is especially remarkable, since I have not used these data as an input of my calibration.

\footnotetext{
${ }^{26}$ See also Autor, Katz, and Kearney (2004).

${ }^{27}$ In the simulations, I find that the fraction of agents with negative wealth, which is about 5 percent at the beginning, rises to about 15 percent at the end of the sample. The final number is in line with the data. For instance, Kennickell (2003, Table 4) reports that 12.3 percent of households had a negative net worth or net worth less than $\$ 1000$ (in 2001 dollars) in the 2001 Survey of Consumer Finances. However, SCF data starting from 1989 do not show changes in the fraction of households with zero or negative net worth from 1989 to 2001 (see Kennickell, 2003).

${ }^{28}$ Trends in wealth inequality in the data are hard to establish, although it seems that wealth inequality increased dramatically in the 1980s and remained high in the 1990s. See Cagetti and De Nardi (2005).

${ }^{29}$ Because of the sampling uncertainty associated with the draws of the idiosyncratic shocks, I report 90 percent confidence bands for the time series generated in presence of idiosyncratic shocks.
} 


\section{Robustness}

I performed a number of robustness checks by changing the parameter values within the context of the benchmark specification. The basic finding from the experiments is that the increase in debt that can be quantitatively explained by the rising earnings dispersion is robust to alternative parameterizations of the model. ${ }^{30}$

Sensitivity to the share of credit constrained agents. The result holds when the income share of the unconstrained agents is assumed to be larger than its benchmark value of 65 percent. However, as the share of unconstrained agents becomes larger, the model generates lower correlations between debt and the data at cyclical frequencies. This is to be expected, because a non-negligible fraction of credit-constrained agents is necessary to generate procyclical debt growth: for instance, under the baseline calibration, the model correlation between debt growth and income growth is 0.55 , similar to the data counterpart of 0.49 . Table 3 reports how this correlation varies when the share of impatient/credit constrained agents changes. As the share of the constrained agents is reduced, the correlation between debt and income growth becomes smaller and smaller. This is to be expected, since aggregate shocks generate little effects on the distribution of financial assets.

Sensitivity to the initial correlation between income and wealth. I verify the sensitivity of the results to the initial value of the cross-sectional correlation between income and financial assets. This is important for two reasons. On the hand, as mentioned in Section 3, there is scant evidence on this number in the 1962 (the earliest) Survey of Consumer Finances. On the other, quadratic cost aside, the model does not generate an endogenous steady state distribution of financial assets, so it is important to verify how the initial conditions shape the subsequent dynamics of the economy. The results are robust to various assumptions about the initial correlation between financial debt and income for the unconstrained group (for the constrained group, this correlation is 1, since borrowing is a constant fraction of housing holdings, which are, in turn, a constant fraction of income). The increase in debt predicted by the model is slightly higher if the initially rich people also have larger values of debt, but the quantitative differences are very small. If I assume that

\footnotetext{
${ }^{30}$ The results are similar when one introduces a quadratic adjustment cost of individual durables in the baseline model. Obviously, this has the effect of smoothing aggregate durables relative to aggregate consumption, but the behavior of household debt is unchanged for reasonable parameterizations of the cost. By making nondurable consumption more volatile, this extension also has the effect of increasing the volatility of the interest rate to magnitudes similar to those in the data.
} 
the initial correlation between income and debt is strongly negative (close to -1 ), the predicted debt-to-income ratio in 2003 is 1.12; in the opposite case (positive initial correlation between debt and income for all agents, including unconstrained agents), the predicted ratio is 1.17. Evidently, the initial conditions do not play a major role in affecting the evolution of debt over time.

Sensitivity to the decomposition of permanent and transitory inequality. In the final experiment, I consider how the behavior of debt depends on the degree of individual income persistence $\rho_{z}$. Given the observed behavior of earnings inequality over time, the persistence of individual incomes is the key determinant in affecting how mobile the individuals are along the income ladder. More persistent income shocks imply, ceteris paribus, less mobility. Table 4 shows the main findings. Interestingly, the increase in debt predicted by the model is a non-monotonic function of the persistence of the individual shocks. In my baseline calibration, I set the autocorrelation of individual shocks to 0.75 : when income inequality rises, the debt to income ratio goes from 0.66 to 1.15. As income shocks become very persistent, individuals are less willing to smooth consumption over time and to accumulate debt or assets via access to the credit market: in the limit, when shock are close to being permanent, a larger volatility of shocks does not imply higher dispersion of financial assets, since individual consumption and income closely track each other; for instance, an autocorrelation of 0.97 implies a final debt to income ratio of 1.03; an autocorrelation of 0.99 implies a final debt to income ratio of 0.71 . When income shocks are too transitory, agents smooth their consumption very often, but their relative position along the income ladder changes substantially every period and so does their demand for financial assets. Because the distribution of financial assets is continuously reshuffled, debt does not display persistence at the aggregate level, and does not rise substantially when income dispersion increases. For instance, iid income shocks imply a rise in the debt to income ratio from 0.66 to 0.82 .

An important conclusion is that the increase in debt during the period 1984-2003 can be explained by the model only if the increased earnings dispersion comes from income shocks that are mean-reverting. Put differently, the increase in inequality that has taken place in the 1980s and 1990s can quantitatively explain the increase in household debt insofar as it has resulted from an increase in the variance of the non-permanent component of earnings.

What do the data say in this regard? Using PSID data, Heathcote, Storesletten, and Violante (2004) decompose the evolution of the cross-sectional variance of earnings over the period 1967-1996 into the variances of fixed effects, persistent shocks, and transitory shocks. They show that the increased earnings variance of the period, say, 1980-1996 can be accounted for by three components 
in roughly equal parts. Following their numbers and specification, I assume that the stochastic component of income is the sum of a very persistent component (with autoregressive coefficient of 0.985$),{ }^{31}$ a persistent one, with persistence equal to 0.85 (the average between my baseline specification and their estimated value for the persistent component), and a purely iid one. The very persistent component mimics changes in inequality coming from fixed/permanent effects, once it is understood that in the model I present here agents can only be interpreted as dynasties (because they live forever), so that the appropriate counterpart of the model's labor income process in the data is not the process for given individuals, but the income process of families. In other words, even if individuals' income processes had a unit root component in the data, one should not calibrate the present kind of model to have a unit root, so long as the intergenerational transmission of earnings is less than perfect. ${ }^{32}$ I then assume than in each year from 1963 to 2003 each of the three components (permanent, persistent and transitory) contributes for one third to the observed inequality change in the Eckstein-Nagypál CPS series. Using this decomposition, the model predicts a slightly smaller increase in the debt-to-income ratio, from 0.66 to 0.96 . The increase in debt predicted by the model is now slightly lower than in the data and in the baseline calibration, mostly because there is less incentive to access the credit market in response to changes in uncertainty coming from the near-permanent component. ${ }^{33}$

\section{Assessing the Accuracy of the Solution: Transitional Dynamics of the Nonlin- ear Model}

The linearization technique adopted so far, although extremely convenient and easy to implement, has the drawback of neglecting the effect of risk on optimal decisions and of ignoring constraints on the asset position that are only occasionally binding. To address these issues, in this section I study the transitional dynamics of a bare-bones version of the model that can be conveniently solved using global approximation schemes.

\footnotetext{
${ }^{31}$ The choice of 0.985 reflects the fact that a shock with such persistence displays a half-life of 45 years, about the typical working life.

${ }^{32}$ Solon (1992), for instance, finds that intergenerational correlation of income is low, roughly 0.35 to 0.40 .

${ }^{33}$ The model assumption that the initial level of inequality comes only from fixed effects simplifies the analysis of the initial steady state, but is not crucial for the results. In experiments not reported here, I also analyzed how the results change when the initial level of inequality is decomposed into fixed and transitory effects. In this case, the initial steady state becomes stochastic rather than deterministic, and one needs to reparameterize the initial steady state accordingly. However, for empirically plausible levels of the initial level of temporary earnings dispersion, the main results of the paper were not affected (Additional details are available upon request).
} 
As in the baseline model, I consider the same economy described in the main text with two groups of agents: patients ( 65 percent of the total) and impatients (35 percent). I allow impatient agents to borrow only up to some fraction $m$ (which I fix at 0.729 ) of their durable holdings, whereas I restrict the maximum borrowing for patient agents so that they can borrow up to 12 times their average endowment. Given the admissible realizations for income, this constraint is only marginally tighter than the natural debt limit, and never binds in the simulations. All the model parameters are those of the baseline version.

First, I compute stochastic steady states for two model parameterizations in absence of aggregate income shocks and financial shocks, one with low inequality, one with high inequality. To ensure comparability with the results of the linearized model, I reverse-engineer the volatility of the individual income shock in the low volatility regime that ensures, given the other model parameters, a debt to income ratio in the stochastic steady state that mimics the data over the period 1963-1980. ${ }^{34}$ The process for log income is assumed to follow a three-state Markov chain, according to the procedure developed in Tauchen (1986). In the low-volatility regime, the possible income realizations are $0.886,1$ and 1.114 . In the high-volatility regime, the corresponding values are 0.715 , 1 and 1.285. The corresponding entries of the transition matrix are:

$$
P=\left[\begin{array}{lll}
0.7756 & 0.2227 & 0.0017 \\
0.1396 & 0.7208 & 0.1396 \\
0.0017 & 0.2227 & 0.7756
\end{array}\right]
$$

These parameter choices imply an autocorrelation of income of 0.75 and a cross-sectional standard deviation of log income of 0.08 in the low volatility regime, 0.21 in the high volatility regime. The change in inequality between the two regimes mimics the increase in inequality in the 1980s and 1990s (the standard deviation of log earnings increases by about 0.15). Because these numbers do not account for the total cross-sectional dispersion of earnings in the data, a maintained assumption here is that residual differences in the initial level of inequality between the model and the data are captured by fixed effects. ${ }^{35}$ The initial earnings dispersion generates a stochastic steady state where the debt to income ratio is 69 percent, as in the data for the year 1980 .

\footnotetext{
${ }^{34}$ To ensure comparability with the dynamics of the linearized model, I set the quadratic bond adjustment cost $\phi=0.0001$ here as well, although - unlike in the linearized model - this cost it is not needed to ensure determinacy and stability of the equilibrium. For each patient agent, the cost is paid whenever asset holding are different from zero. As in the linearized model, this cost has no major effect on the dynamics of the model, but has the effect of reducing somewhat the dispersion of assets in the stochastic steady state of the model.

${ }^{35}$ In experiments not reported here, I found that the results were essentially similar for different decompositions of the dispersion due to fixed effects vis-à-vis transitory shocks.
} 
Figure 11 plots the resulting decision rules ${ }^{36}$ in the stochastic steady state of the low and high inequality regimes (the income state is assumed to be the median one). For the patient agents (top panel) the decision rules for borrowing - the amount of financial liabilities carried into next period as a function of today's cash-on-hand, defined as coh $=(1-\delta) h-R b$ - are essentially linear for plausible values of $c o h$, from -10 (indicating a financial asset to income ratio of 10) to +10 (indicating borrowing ten times as large as average income, a value that is almost never achieved in the simulations, given the mean reverting properties of the income shock). In addition the two decision rules lie virtually on top of each other: ${ }^{37}$ partial equilibrium reasoning suggests that, with high volatility, patient agents should borrow less; however, the equilibrium interest rate is lower in the high volatility case, thus providing agents with an extra incentive to borrow; quantitatively, these two effects roughly cancel with each other. For impatient agents (bottom panel), the decision rules show that the optimal borrowing to housing ratio is always close to the maximum loan-to-value ratio for low values of their cash on-hand. In the simulations, these agents spend all of their time in the upward sloping region of the policy function (borrowing more whenever their cash-on-hand increases, and borrowing up to the maximum loan to value ratio).

Next I turn to the transitional dynamics. I assume that in 1981 income dispersion rises unexpectedly to a new, higher level (following an increase in the variance of the innovations to the income process), which agents expect to persist forever, and then I compute the transition path of the economy following this change. In terms of the experiment, the only difference with the linearized model is that here the change in inequality is assumed to be a one-off episode, ${ }^{38}$ whereas in linearized model it happens more gradually. Figure 12 plots the results of this exercise. In the top panel, inequality of earnings rises unexpectedly in $1981 .^{39}$ Over time, agents engage in more

\footnotetext{
${ }^{36} \mathrm{I}$ approximate the demand for financial assets from each group by a continuous, piece-wise linear function. To find the steady state, I use simulated series and a Newton-type algorithm. For a given interest rate, I compute individual asset demands and simulate $N=1,000$ Markov chains of length $T=8,000$ periods for the income shock (35 percent for the impatient agents and 65 percent for the patient agents). In the last period, I calculate aggregate excess demand for net financial assets and then update the interest rate until the credit market clears.

${ }^{37}$ I say "essentially" because individual borrowing is on average 0.10 higher in low inequality than in the high inequality case, reflecting standard precautionary saving motives. However, in the high inequality case agents are more spread out in terms of income and cash-on-hand, and this effect more than dominates the effect caused by the increased precautionary saving.

${ }^{38}$ Some studies have argued that much of change in inequality in the United States was concentrated in the 19801985 period (e.g. Card and Lemieux, 1994). Supporters of this view will like this experiment more.

${ }^{39}$ The algorithm that I use to compute the transition between steady states follows Ríos-Rull (1999) with minor modifications. I assume that the economy reaches the new steady state in 100 years, that is in year 2080. I then guess a sequence of prices $\left\{R_{t}\right\}$ for $t=\{1981,1983 \ldots, 2080\}$. Given the policy functions calculated at $t=2080$, I compute
} 
"consumption smoothing activities", and debt starts rising gradually. ${ }^{40}$ In the bottom panel, the increase in debt is of similar magnitude to the data, thus confirming the accuracy of the linearized model. In particular, the debt to income ratio predicted for 2003 is 102 percent. Not plotted in the figure, the final debt to income ratio in the stochastic steady state (achieved around year 2050) is 149 percent. Hence, according to the model, debt would continue to rise before stabilizing to a higher level even if income inequality were to remain constant in the future at 2003 level. ${ }^{41}$

\section{Conclusions}

This paper has constructed and simulated a heterogeneous agents model that mimics the distribution of income in the United States in the period 1963-2003. Such a model can explain remarkably well the endogenous dynamics of household debt. The rise in income inequality of the 1980s and the 1990s can, at the same time, account for the increase in household debt, the large widening of wealth inequality, and the relative stability of consumption inequality.

As to the consumption inequality result, one related paper is Krueger and Perri (2006). They argue that, in the data, consumption inequality has risen much less than income inequality. They present a model of endogenous market incompleteness in which the incentive to trade assets is directly related to the uncertainty faced at the individual level. They show that only such a model is able to predict a modest decrease in within-group consumption inequality alongside an increase in between-group consumption inequality. In the model presented here, the mechanism through which consumption inequality rises less than income inequality in an expansion of credit from the rich to the poor. The emphasis on the business cycle implications of household debt, instead, has policy functions and decision rules for $t=\{2079,2078 \ldots, 1981\}$ by iterating backwards in time. I then simulate the distribution forward for the transition path starting at $t=1981$, and check whether the credit market clear at each point during the transition (if not, I use a Gauss-Seidel algorithm to make a new guess for $\left\{R_{t}\right\}$ until convergence). Typically, convergence is achieved after 50 periods, so the number of transition periods is not affecting the results.

${ }^{40}$ Not shown in the picture, the interest rate first undershoots and then converges to a new, lower steady state value from below.

${ }^{41}$ Risk aversion could potentially play a bigger role in the non-linear model, where high risk aversion implies, ceteris paribus, a more "concave" consumption function. I have analyzed what happens if risk aversion rises to a larger value (working with a per-period utility function of the form $u=\left(c \times h^{j}\right)^{1-\sigma} /(1-\sigma)$, that nests the log-log case in the text when $\sigma$ approaches unity). High risk aversion (say a coefficient of risk aversion of $\sigma=3$ ) implies a lower interest rate and a higher level of aggregate debt to income. Following an increase in uncertainty, total debt rises by an amount that is quantitatively similar to that in case of log utility. This happens because, in spite of the higher risk aversion, agents operate in a region of the consumption function where the policy functions are essentially linear, and because their behavior is guided mainly by intertemporal concerns rather than by insurance motives. 
also been analyzed by Campbell and Hercowitz (2005). They show how a business cycle model with endogenous labor supply and time-varying collateral constraints can account for lower volatility of output and debt when collateral constraints are relaxed.

The modeling setup presented here shares common ground with the literature on general equilibrium models with idiosyncratic risk and incomplete markets. Most of the papers in this spirit have mainly focused on the ability of this class of models to explain the distribution of consumption, income, and wealth (for instance Huggett (1993), Aiyagari (1994) and Castaneda, Díaz-Giménez, and Ríos-Rull (2003)), and on the role that heterogeneity plays in affecting macroeconomic outcomes (see for instance Krusell and Smith (1998)). In my paper, the emphasis is instead on the behavior of a variable (household debt) that has received very little attention in this class of models. To keep the model simple and tractable, I stay away from the important question of whether micro heterogeneity amplifies macroeconomic shocks: extensions to allow for these elements would be worthwhile ideas. Of course, it would be also interesting to see how the model results are affected when additional elements of realism are introduced. In this vein, variable collateral prices and overlapping generations considerations also appear plausible candidates to fill the gap between the model and reality. ${ }^{42}$

\footnotetext{
${ }^{42}$ Using an Aiyagari-style model with overlapping generations, Heathcote, Storesletten, and Violante (2004) show that the changing relative importance of permanent versus transitory shocks to wages over has important implications for the extent to which wage inequality translates into consumption inequality. Nakajima (2005) uses a similar OLG setup to study the effects of rising earnings instability on mortgage debt and housing prices.
} 


\section{References}

[1] Aiyagari, S. Rao (1994), "Uninsured Idiosyncratic Risk and Aggregate Saving," Quarterly Journal of Economics, 109, 3, 659-684.

[2] Aizcorbe, Ana M., Arthur B. Kennickell, and Kevin B. Moore (2003), "Recent Changes in U.S. Family Finances: Evidence from the 1998 and 2001 Survey of Consumer Finances," Federal Reserve Bulletin, 89, January, 1-32.

[3] Autor, David, Lawrence F. Katz, and Melissa S. Kearney (2004), "U.S. Wage and Consumption Inequality Trends: A Re-Assessment of Basic Facts and Alternative Explanations," working paper, Massachusetts Institute of Technology.

[4] Brav, Alon, George M. Constantinides, and Christopher C. Geczy (2002), "Asset Pricing with Heterogeneous Consumers and Limited Participation: Empirical Evidence," Journal of Political Economy, 110, 793-824.

[5] Cagetti, Marco, and Mariacristina De Nardi (2005), "Wealth Inequality: Data and Models," working paper, Federal Reserve Bank of Chicago.

[6] Campbell, John Y. and Gregory N. Mankiw (1989), "Consumption, Income and Interest Rates: Reinterpreting the Time Series Evidence," in Olivier J. Blanchard and Stanley Fisher, eds., NBER Macroeconomics Annual 1989, Cambridge: MIT Press, 185-216.

[7] Campbell, Jeffrey, and Zvi Hercowitz (2005), "The Role of Collateralized Household Debt in Macroeconomic Stabilization," NBER Working Paper 11330.

[8] Card, David, and John E. DiNardo (2002), "Skill-Biased Technological Change and Rising Wage Inequality: Some Problems and Puzzles," Journal of Labor Economics, 20, 4, 733-783.

[9] Card, David, and Thomas Lemieux (1994), "Changing Wage Structure and Black-White Wage Differentials," American Economic Review Papers and Proceedings, 84, 2, 29-33.

[10] Castaneda, Ana, Javier Díaz-Giménez, and Victor Ríos-Rull (2003), “Accounting for the U.S. Earnings and Wealth Inequality," Journal of Political Economy, 111, 4, 818-857.

[11] Den Haan, Wouter J. (1997), "Solving Dynamic Models with Aggregate Shocks and Heterogeneous Agents," Macroeconomic Dynamics, 1, 355-386. 
[12] Eckstein, Zvi and Eva Nagypál (2004), "The Evolution of U.S. Earnings Inequality: 19612002," Federal Reserve Bank of Minneapolis Quarterly Review, 28, 2, December, 10-29.

[13] Frederick, Shane, George Loewenstein, and Ted O’Donoghue (2002), "Time Discounting and Time Preference: A Critical Review," Journal of Economic Literature, 40, 2, 351-401.

[14] Heathcote, Jonathan, Kjetil Storesletten, and Gianluca Violante (2004), "The Macroeconomic Implications of Rising Wage Inequality in the United States," working paper, Georgetown University.

[15] Heaton, Jonathan, and Deborah Lucas (1996), "Evaluating the Effect of Incomplete Markets on Risk Sharing and Asset Pricing," Journal of Political Economy, 104, 443-487.

[16] Huggett, Mark (1993), "The Risk Free Rate in Heterogeneous-Agents, Incomplete Insurance Economies," Journal of Economic Dynamics and Control, 17, 5/6, 953-970.

[17] Iacoviello, Matteo (2005), "House Prices, Borrowing Constraints and Monetary Policy in the Business Cycle," American Economic Review, 95, 3, 739-764.

[18] Jappelli, Tullio (1990), "Who Is Credit Constrained in the U.S. Economy?," Quarterly Journal of Economics, 105, 219-234.

[19] Katz, Lawrence, and David Autor (1999), "Changes in Wages Structure and Earnings Inequality," in Oscar Ashenfelter and David Card, eds., Handbook of Labor Economics, Amsterdam: Elsevier.

[20] Kennickell, Arthur B., and Janice Shack-Marquez (1992), "Changes in family finances from 1983 to 1989: Evidence from the Survey of Consumer Finances," Federal Reserve Bulletin, January, 1-18.

[21] Kennickell, Arthur B. (2003), "A Rolling Tide: Changes in the Distribution of Wealth in the U.S., 1989 to 2001," working paper, Federal Reserve Board.

[22] Krueger, Dirk, and Fabrizio Perri (2006), "Does Income Inequality Lead to Consumption Inequality? Evidence and Theory," Review of Economic Studies, 73, 1, 163-194.

[23] Krusell, Per, Burhanettin Kuruşçu, and Anthony A. Smith, Jr. (2001), "Time Orientation and Asset Prices," Journal of Monetary Economics, 49, 107-35. 
[24] Krusell, Per, and Anthony A. Smith, Jr. (1998), "Income and Wealth Heterogeneity in the Macroeconomy," Journal of Political Economy, 106, 867-896.

[25] Lawrence, Emily, (1991), "Poverty and the Rate of Time Preference: Evidence from Panel Data," Journal of Political Economy, 119, 54-77.

[26] Lemieux, Thomas (2006), "Increasing Residual Wage Inequality: Composition Effects, Noisy Data, or Rising Demand for Skill?," American Economic Review, 96, 3, 461-498.

[27] Ludvigson Sydney (1999), "Consumption and Credit: a Model of Time-Varying Liquidity Constraints," The Review of Economics and Statistics, 81, 3, 434-447.

[28] Moffitt, Robert A., and Peter Gottschalk (2002), "Trends in the Transitory Variance of Earnings in the United States," The Economic Journal, 112, C68-C73.

[29] Nakajima, Makoto (2005), "Rising Earnings Instability, Portfolio Choice, and Housing Prices," manuscript, University of Illinois Urbana-Champaign.

[30] Piketty, Thomas, and Emmanuel Saez (2003), "Income Inequality in the United States, 19131998," Quarterly Journal of Economics, 1, 1-39.

[31] Ríos-Rull, Victor (1999), "Computation of Equilibria in Heterogeneous-Agents Models," in Ramon Marimon and Andrew Scott, eds., Computational Methods for the Study of Dynamic Economies, New York: Oxford University Press.

[32] Samwick, Andrew A. (1998), "Discount Rate Heterogeneity and Social Security Reform." Journal of Development Economics, 57, 1, 117-146.

[33] Solon, Gary (1992). "Intergenerational Income Mobility in the United States," American Economic Review, 82, 3, 393-408.

[34] Storesletten, Kjetil, Chris I. Telmer, and Amir Yaron (2004), "Cyclical Dynamics in Idiosyncratic Labor-market Risk," Journal of Political Economy, 112, 3, 695-718.

[35] Tauchen, George (1986), "Finite State Markov-Chain Approximations to Univariate and Vector Autoregressions," Economics Letters, 20, 177-81.

[36] Warner, John T., and Saul Pleeter (2001), "The Personal Discount Rate: Evidence from Military Downsizing Programs," American Economic Review, 91, 1, 33-53. 


\section{Appendix A: Data description and treatment}

\section{Description}

- The disposable personal income series are produced by the BEA.

The nominal and real series are available at the FRED2 website respectively at:

- http://research.stlouisfed.org/fred2/series/dpi

- http://research.stlouisfed.org/fred2/series/dpic96

The ratio between the two series is used to construct the deflator of nominal debt.

- Data on total household (end of period, outstanding) debt are from the Flow of Funds Z1 release. The series is also available through FRED2 at

- http://research.stlouisfed.org/fred2/series/CMDEBT

Data on household debt service and financial obligations ratios are available at

- http://www.federalreserve.gov/releases/housedebt/default.htm

The breakdown of total household debt into mortgage and consumer debt is in the Flow of Funds Z1 release, Table D.3, available at

- http://www.federalreserve.gov/releases/z1/Current/Disk/gtabs.zip

Data on home equity loans are in Table L.218.

- Data on loan-to-value ratios are taken from the Federal Housing Finance Board. The loan-to-price ratio measure refers to newly-built homes. It is available at

- http://www.fhfb.gov/GetFile.aspx?FileID=4121

- Data on inequality are from Eckstein and Nagypál (2004), using data drawn from the March Current Population Survey, and refers to the standard deviation of pre-tax log wages of full-time, full-year male workers. Measures of inequality based on different data sets or different samples show the same pattern. The Eckstein-Nagypál series ends in 2002. I extrapolate the data for 2003 using earnings inequality data taken from the U.S. Census Bureau website. The original series is available at

- http://faculty.wcas.northwestern.edu/ een461/QRproject/stdev-final.xls

\section{Treatment}

In the data, there is trend growth in disposable personal income (DPI), which I account for by detrending real DPI using a bandpass filter that isolates frequencies between 1 and 8 years. I then construct a deflated, detrended household debt series dividing the original household debt series by trend in DPI. In other words:

$$
\begin{aligned}
\frac{B}{Y} & =\frac{\text { nominal debt }}{\text { nominal DPI }} \\
P & =\text { deflator }=\frac{\text { nominal DPI }}{\text { real DPI }}=\frac{Y}{y} \\
\widehat{y} & =\text { detrended real DPI }=\frac{\text { real DPI }}{\text { trend real DPI }}=\frac{y}{\widetilde{y}} \\
\widehat{b} & =\text { detrended real debt }=\frac{\text { nominal debt } / \text { deflator }}{\text { trend real DPI }}=\frac{B / P}{\widetilde{y}} .
\end{aligned}
$$

The advantage of this procedure is that detrended real debt shows the same trend over time as the original $B / Y$ series plotted in Figure 1. The first difference of $\log$ detrended real debt $\Delta(\log \widehat{b})$ can then be used to compare debt growth in the data with debt growth in the model (see Figure 7). 


\section{Appendix B: Recovering the idiosyncratic shocks}

\section{Notation and assumptions}

This Section describes how I back out the idiosyncratic income shocks that are able to replicate the observed behavior of income dispersion over time. There are $N$ individuals, for $T$ periods. Starting at time $t=1$, I specify the following law of motion for individual incomes:

$$
\log y_{i t}=\log a_{t}+\log f_{i}+\log z_{i t}
$$

where $f_{i}$ is an individual specific fixed effect, $a_{t}$ is a log-normally distributed aggregate disturbance, and the timevarying, individual-specific effect $z_{i t}$ follows a process of the form:

$$
\log z_{i t}=\rho_{z} \log z_{i t-1}+e_{i t} .
$$

At $t=1$, I normalize $\log a_{1}=0$, so the level of aggregate productivity is 1 . The other two terms have the following representation:

$$
\begin{aligned}
e_{i t} & \sim N\left(-x_{t}, v_{t}^{2}\right) \\
\log f_{i} & \sim N\left(-s^{2} / 2, s^{2}\right) .
\end{aligned}
$$

The variance of the time-varying shocks $v_{t}$ is allowed to change over time, thus affecting the cross-sectional dispersion of earnings over time. The term $x_{t}$ is a time-varying factor that ensures that the mean level of $z$ is unity for all $t .^{43}$ At $t=1$, I let the economy be in steady state, that is, $\log a_{t}=0$ and $e_{i 1}=0$ for all $i$ 's. This implies:

$$
\begin{aligned}
\log y_{i 1} & =\log f_{i} \\
E\left(y_{1}\right) & \equiv \frac{1}{N} \sum_{i=1}^{N} y_{i 1}=1
\end{aligned}
$$

\section{Backing out the $x$ 's and the $v$ 's}

Absent aggregate shocks (which, by construction, do not affect the dispersion of log earnings), it is straightforward to calculate the conditions under which mean level income will be unity for all $t$. At time $t=2$ :

$$
\begin{aligned}
E\left(\log z_{2}\right) & =E\left(e_{2}\right) \\
\log z_{i 2} & \sim N\left(-x_{2}, v_{2}^{2}\right) \\
E\left(z_{2}\right) & =\exp \left(-x_{2}+v_{2}^{2} / 2\right)=1 \text { if } x_{2}=v_{2}^{2} / 2 \\
& \Longrightarrow e_{2}=\log z_{2} \sim N\left(-v_{2}^{2} / 2, v_{2}^{2}\right) .
\end{aligned}
$$

Next period, when $t=3$, we have:

$$
\begin{aligned}
E\left(\log z_{3}\right) & =\rho E\left(\log z_{2}\right)+E\left(e_{3}\right) \\
\log z_{2} & \sim N\left(-v_{2}^{2} / 2, v_{2}^{2}\right) \\
e_{3} & \sim N\left(-x_{3}, v_{3}^{2}\right) \\
\log z_{3} & \sim N\left(-\rho_{z} v_{2}^{2} / 2-x_{3}, \rho_{z}^{2} v_{2}^{2}+v_{3}^{2}\right) \\
E\left(z_{3}\right) & =\exp \left(-\rho_{z} v_{2}^{2} / 2-x_{3}+\left(\rho_{z}^{2} v_{2}^{2}+v_{3}^{2}\right) / 2\right)=1 \text { if } x_{3}=\left(v_{3}^{2}-\rho_{z}\left(1-\rho_{z}\right) v_{2}^{2}\right) / 2 \\
& \Longrightarrow e_{3} \sim N\left(-\left(v_{3}^{2}-\rho_{z}\left(1-\rho_{z}\right) v_{2}^{2}\right) / 2, v_{3}^{2}\right) \\
& \Longrightarrow \log z_{3} \sim N\left(-\left(\rho_{z}^{2} v_{2}^{2}+v_{3}^{2}\right) / 2, \rho_{z}^{2} v_{2}^{2}+v_{3}^{2}\right) .
\end{aligned}
$$

\footnotetext{
${ }^{43}$ Were $x_{t}$ equal to zero in all periods, the properties of the log-normal distribution would imply that a higher dispersion of log-incomes would increase the mean of income.
} 
By the same reasoning, at time $t=4$, one finds that:

$$
\begin{aligned}
E\left(\log z_{4}\right) & =\rho E\left(\log z_{3}\right)+E\left(e_{4}\right) \\
\log z_{3} & \sim N\left(-\left(\rho_{z}^{2} v_{2}^{2}+v_{3}^{2}\right) / 2, \rho_{z}^{2} v_{2}^{2}+v_{3}^{2}\right) \\
e_{4} & \sim N\left(-x_{4}, v_{4}^{2}\right) \\
\log z_{4} & \sim N\left(-\rho_{z}\left(\rho_{z}^{2} v_{2}^{2}+v_{3}^{2}\right) / 2-x_{4}, \rho_{z}^{2}\left(\rho_{z}^{2} v_{2}^{2}+v_{3}^{2}\right)+v_{4}^{2}\right) \\
E\left(z_{4}\right) & =1 \text { if } x_{4}=\left(v_{4}^{2}-\rho_{z}\left(1-\rho_{z}\right) v_{3}^{2}-\rho_{z}^{3}\left(1-\rho_{z}\right) v_{2}^{2}\right) / 2 \\
E\left(\log z_{4}\right) & =-\left(v_{4}^{2}+\rho_{z}^{2} v_{3}^{2}+\rho_{z}^{4} v_{2}^{2}\right) / 2 .
\end{aligned}
$$

Hence the pattern of the $x$ 's over time obeys the following formulas:

$$
\begin{aligned}
x_{1}= & 0 \\
x_{2}= & v_{2}^{2} / 2 \\
x_{3}= & \left(v_{3}^{2}-\rho_{z}\left(1-\rho_{z}\right) v_{2}^{2}\right) / 2 \\
x_{4}= & \left(v_{4}^{2}-\rho_{z}\left(1-\rho_{z}\right) v_{3}^{2}-\rho_{z}^{3}\left(1-\rho_{z}\right) v_{2}^{2}\right) / 2 \\
& \cdots \\
x_{t}= & \left(v_{t}^{2}-\rho_{z}\left(1-\rho_{z}\right) \sum_{i=0}^{t-1}\left(\rho_{z}^{2(t-1-i)} v_{i}^{2}\right)\right) / 2 .
\end{aligned}
$$

\section{The implied volatility of earnings}

In each period $t$, assuming that the $v_{i t}$ shocks are uncorrelated over time and with the fixed effect, the cross-sectional variance of log earnings will be given by:

$$
\operatorname{var}\left(\log y_{t}\right)=\operatorname{var}(\log f)+\operatorname{var}\left(\log z_{t}\right)
$$

where

$$
\operatorname{var}\left(\log z_{t}\right)=\rho_{z}^{2} \operatorname{var}\left(\log z_{t-1}\right)+v_{t}^{2}
$$

and for each variable $x_{i t}$ the variance is taken with respect to the $i$ 's, that is:

$$
\operatorname{var}\left(x_{t}\right) \equiv \frac{1}{N}\left(\sum_{i=1}^{N} x_{i t}-\frac{1}{N} \sum_{i=1}^{N} x_{i t}\right)^{2} .
$$

Let the economy be in the non-stochastic steady state at time $t=1$. At time $t=1$, if $e_{i 1}=1$ for all $i$, we have that $v_{1}=0$ and

$$
\operatorname{var}\left(\log y_{1}\right)=s^{2}
$$

At time $t=2$, let $v_{2}>0,{ }^{44}$ so that

$$
\operatorname{var}\left(\log y_{2}\right)=s^{2}+v_{2}^{2}
$$

At time $t=3, \operatorname{var}\left(\log z_{3}\right)=\rho_{z}^{2} v_{2}^{2}+v_{3}^{2}$, so that

$$
\operatorname{var}\left(\log y_{3}\right)=s^{2}+\rho_{z}^{2} v_{2}^{2}+v_{3}^{2}
$$

\footnotetext{
${ }^{44}$ This procedure applies to cases where income inequality rises from the initial steady state. In periods in which income inequality falls sharply, it needs to be modified to allow for a negative correlation between fixed effects and $v$ shocks.
} 
Given observations over time on $\operatorname{var}\left(\log y_{i t}\right)$, the last three equations and so on for each period $t$ can be used to construct in each period the vector of individual income shocks $v$, which generates the desired pattern of log-income variances. That is

$$
\begin{aligned}
v_{1}= & 0 \\
v_{2}^{2}= & \operatorname{var}\left(\log y_{2}\right)-s^{2} \\
v_{3}^{2}= & \operatorname{var}\left(\log y_{3}\right)-\rho_{z}^{2} \operatorname{var}\left(\log y_{2}\right)-\left(1-\rho_{z}^{2}\right) \operatorname{var}(\log f) \\
& \ldots \\
v_{t}^{2}= & \operatorname{var}\left(\log y_{t}\right)-\rho_{z}^{2} \operatorname{var}\left(\log y_{t-1}\right)-\left(1-\rho_{z}^{2}\right) s^{2} .
\end{aligned}
$$

\section{Implementation of the algorithm used to calculate the vector of shocks}

The algorithm used to back out the individual income shocks goes through the following steps:

1. Given a $T \times 1$ time-series vector of data on income dispersion $\operatorname{var}\left(\log y_{t}\right)$, set the variance of the initial fixed effects so that

$$
\operatorname{var}(\log f)=\operatorname{var}\left(\log y_{1}\right)=s^{2}
$$

where $\operatorname{var}\left(\log y_{1}\right)$ is the variance of log earnings at time 1 . This is done by using a random number generator that creates an $N \times 1$ vector of observations on $\log f$ with variance exactly equal to $s^{2}$ (and mean equal to $-s^{2} / 2$, so that the steady state average income level is unity). This is done by sampling a random vector $N \times 1$ from a $(0,1)$ normal distribution, standardizing the vector, multiplying the vector by $s$, and subtracting $s^{2} / 2$.

2. Assign a value to $\rho_{z}$, the autocorrelation of the income shocks. Construct the $T \times 1$ vector of cross-sectional variances $v_{t}^{2}$ using data on $\operatorname{var}\left(\log y_{t}\right)$ using the formulas of the previous Subsection.

3. Using the time-series vector $v_{t}^{2}$, construct recursively the series $x_{t}$.

4. Construct the $T \times N$ matrix (e) of i.i.d. shocks over time having, for each period $t$, variance equal to $v_{t}^{2}$ and mean equal to $x_{t}$. To correct for sampling error, go as follows:

1. At time 1 , set all of the first row of $e\left(e_{1}\right)$ equal to zero.

2. Construct the second row $\left(\mathbf{e}_{2}\right)$ of i.i.d. shocks corresponding to $t=2$ by generating a random vector of length $N$.

3. Ensure that $e_{2}$ is orthogonal to $\log f$ by constructing $\widehat{\mathbf{e}_{2}}$, the residuals of a regression of $e_{2}$ on a constant term and $\log f$. Normalize $\widehat{\mathbf{e}_{2}}$ so that it has mean equal to $x_{2}$ and variance equal to $v_{2}^{2}$. Let the resulting vector be $\widetilde{\mathbf{e}_{2}}$

4. For each successive period, construct $e_{t}$ so that it is orthogonal to $\log f$ and $\widetilde{\mathbf{e}_{t-1}}, \widetilde{\mathbf{e}_{t-2}}$ and so on.

5. Consistent with the value of $\rho_{z}$, for each $i$, the time series of length $T$ of income sequences $\log z_{i t}$ is formed using:

$$
\log z_{i t}=\rho_{z} \log z_{i t-1}+e_{i t}
$$




\begin{tabular}{ccc}
\hline \hline Parameter & Interpretation & Value \\
\hline$\gamma$ & Discount factor, impatient agents & 0.865 \\
$\beta$ & Discount factor, patient agents & 0.965 \\
$j$ & Weight on durables/housing in utility function & 0.117 \\
$\delta$ & Housing depreciation rate & 0.04 \\
$m$ & Loan-to-value ratio & 0.729 \\
$n / N$ & Fraction of unconstrained agents & 0.65 \\
& Fraction of creditors & 0.35 \\
\hline
\end{tabular}

Table 1: Calibrated Parameter Values

\begin{tabular}{cccc}
\hline \hline & \multicolumn{3}{c}{ Standard deviation } \\
& All agents & Unconstrained & Constrained \\
Individual consumption growth & 0.0794 & 0.029 & 0.173 \\
Individual income growth & 0.224 & 0.224 & 0.224 \\
& & & \\
Interest rate & \multicolumn{3}{c}{ Standard deviation } \\
Aggregate consumption growth & 0.0035 & \\
Aggregate income growth & 0.014 & \\
\hline
\end{tabular}

Table 2: Summary Statistics on Individual Income and Consumption Volatility.

\begin{tabular}{cc}
\hline \hline Fraction of unconstrained agents & $\operatorname{Corr}\left(\frac{\Delta D}{D}, \frac{\Delta Y}{Y}\right)$ \\
\hline 0.90 & 0.09 \\
0.75 & 0.23 \\
0.65 & 0.55 \\
0.55 & 0.60 \\
& \\
\hline Data & 0.49 \\
\hline
\end{tabular}

Table 3: Sensitivity to the Share of Unconstrained Agents.

Note: The second column shows how the correlation between debt growth and income growth changes as a function of the share of patient/unconstrained. The last row reports the sample correlation between year-on-year debt growth and income growth in the data. 


\begin{tabular}{ccccc}
\hline \hline Persistence of shock $\rho_{z}$ & $(D / Y)_{63}$ & $(D / Y)_{83}$ & $(D / Y)_{03}$ & Corr $\frac{\Delta D}{D}$ model,data \\
\hline 0 & 0.66 & 0.66 & 0.82 & 0.45 \\
0.25 & 0.66 & 0.67 & 0.89 & 0.46 \\
0.5 & 0.66 & 0.69 & 0.99 & 0.46 \\
0.65 & 0.66 & 0.71 & 1.07 & 0.46 \\
0.75 & 0.66 & 0.72 & 1.15 & 0.46 \\
0.85 & 0.66 & 0.74 & 1.23 & 0.46 \\
0.95 & 0.66 & 0.72 & 1.17 & 0.47 \\
0.97 & 0.66 & 0.69 & 1.03 & 0.46 \\
0.99 & 0.66 & 0.65 & 0.71 & 0.42 \\
\hline Data & & & & \\
\hline
\end{tabular}

Table 4: Sensitivity to the Persistence of the Individual Income Process.

Note: Columns 2 to 4 show the predicted aggregate debt-to-income ratios in 1963, 1983, and 2003, respectively, as a function of the degree of individual income persistence. The last column reports the sample correlation between year-on-year debt growth in the data and in the model. 
FIGURE 1: The Data
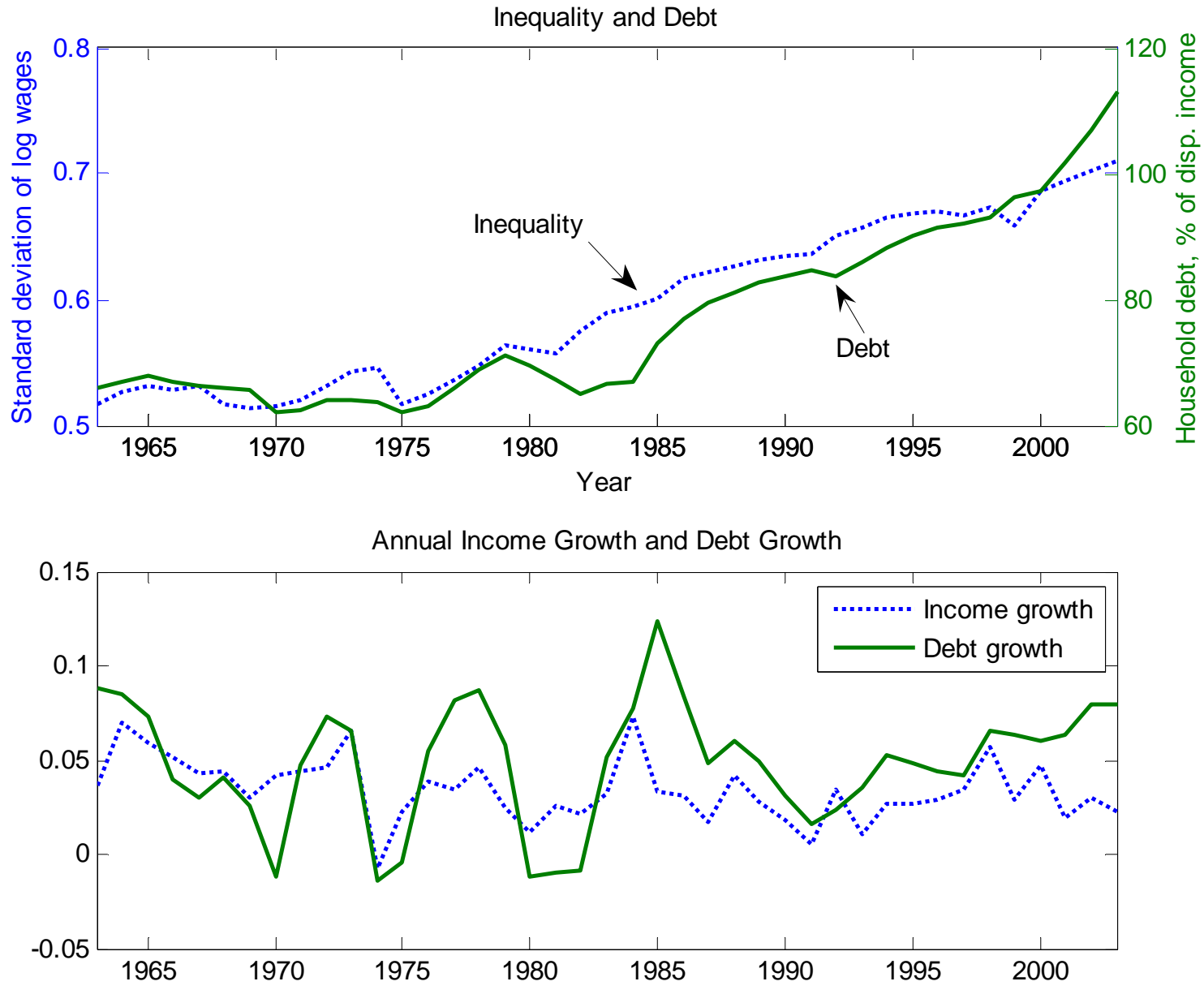

Note: See text and Appendix B for data definitions and sources. In the bottom panel, both series have been deflated using the implicit price deflator for personal consumption expenditures. 
FIGURE 2: Initial and Final Earnings and Debt Positions in a Typical Simulation
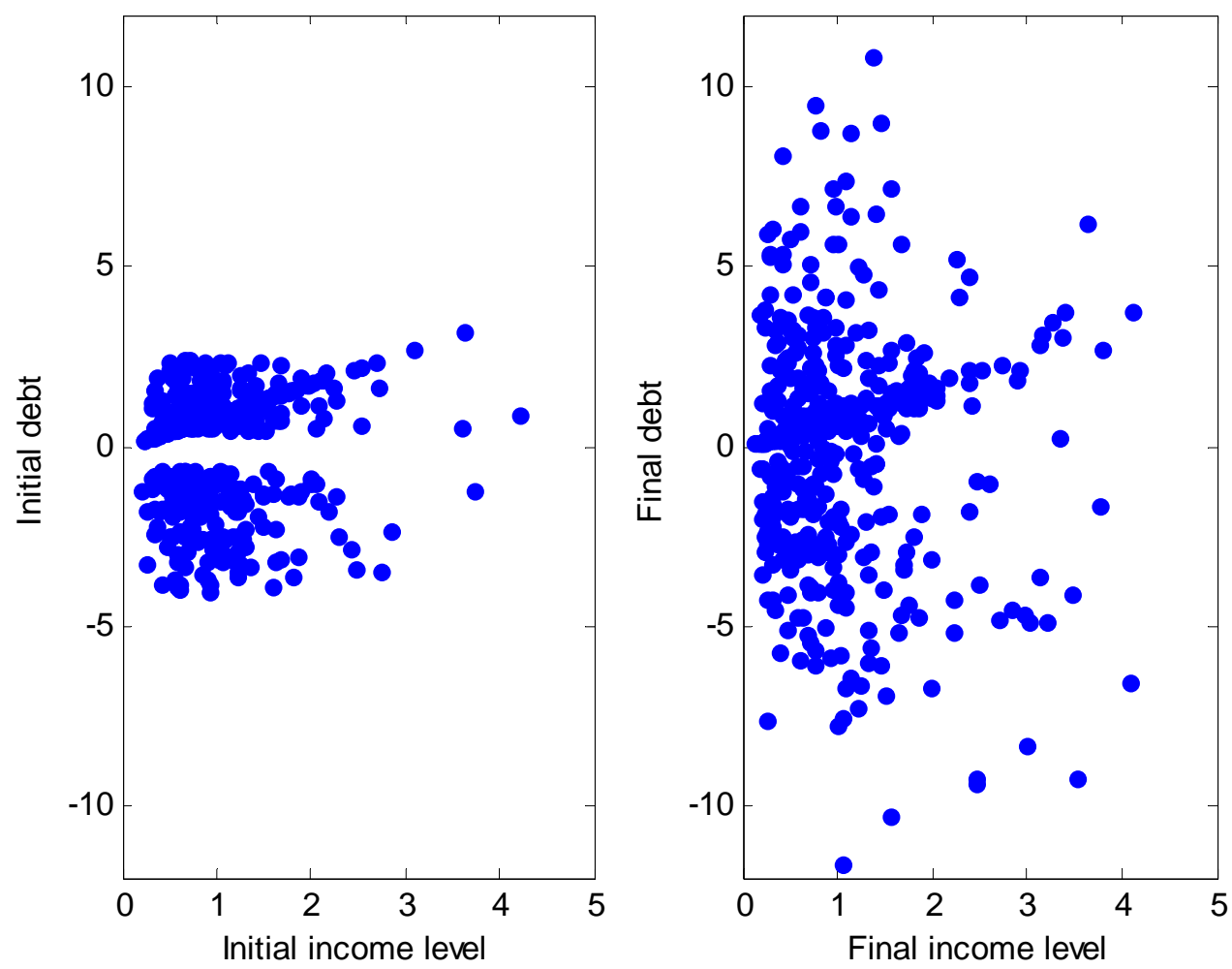

Notes: Each dot on the diagram represents an individual debt-income position. Negative values of debt indicate positive financial assets. 
FIGURE 3: The Stochastic Processes for Aggregate Income and the Loan-to-Value Ratio

The aggregate income process

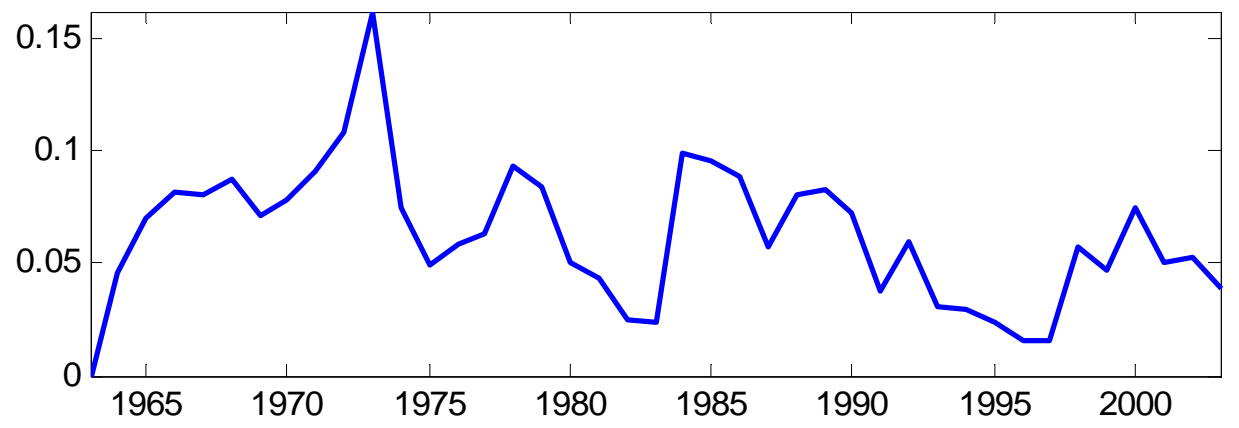

The financial shock process

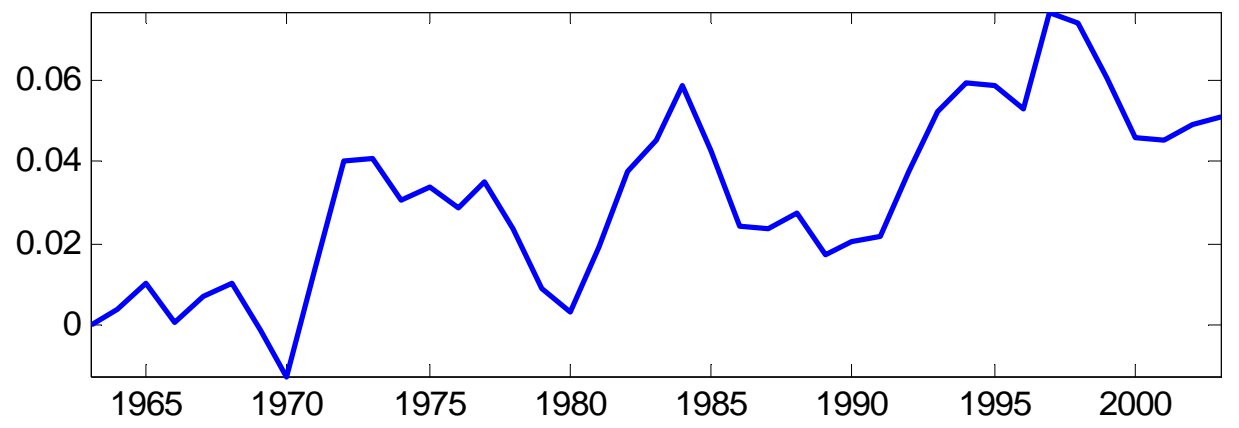

Notes: The variables are expressed in percent deviations from the initial steady state. 
FIGURE 4: Earnings, Consumption and Debt Profiles for an Unconstrained and a Constrained Agent in a Typical Simulation

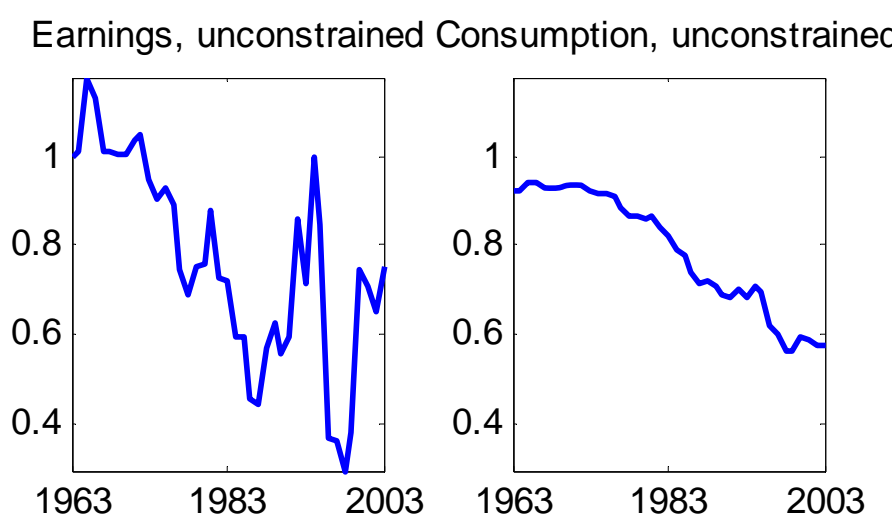

Debt, unconstrained

Earnings, constrained

Consumption, constrained
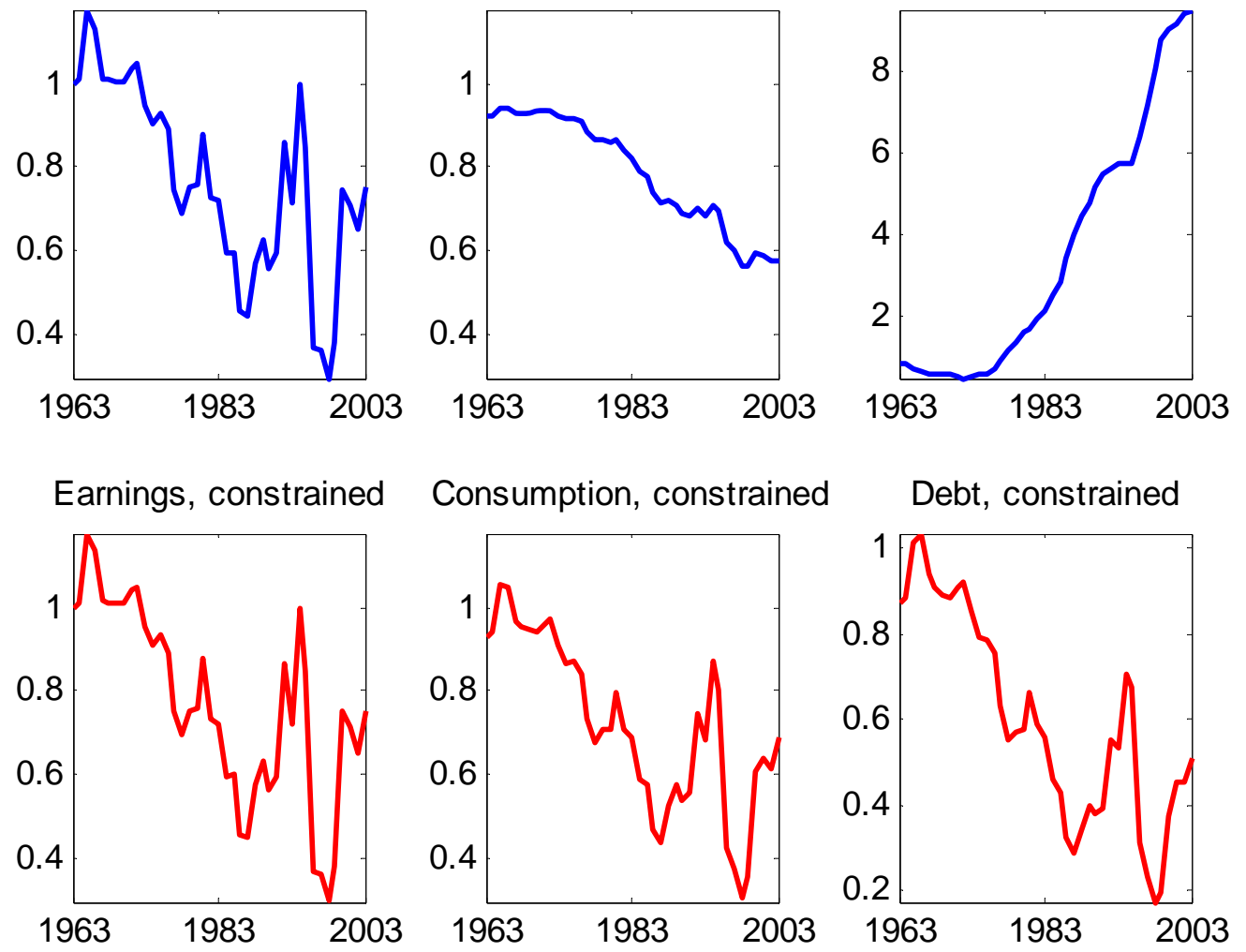

Note: All variables are in levels. Both agents are assumed to start with the same debt and income and are subject to the same shocks during the simulation period. 
FIGURE 5: Simulated Time Series for the Macroeconomic Aggregates

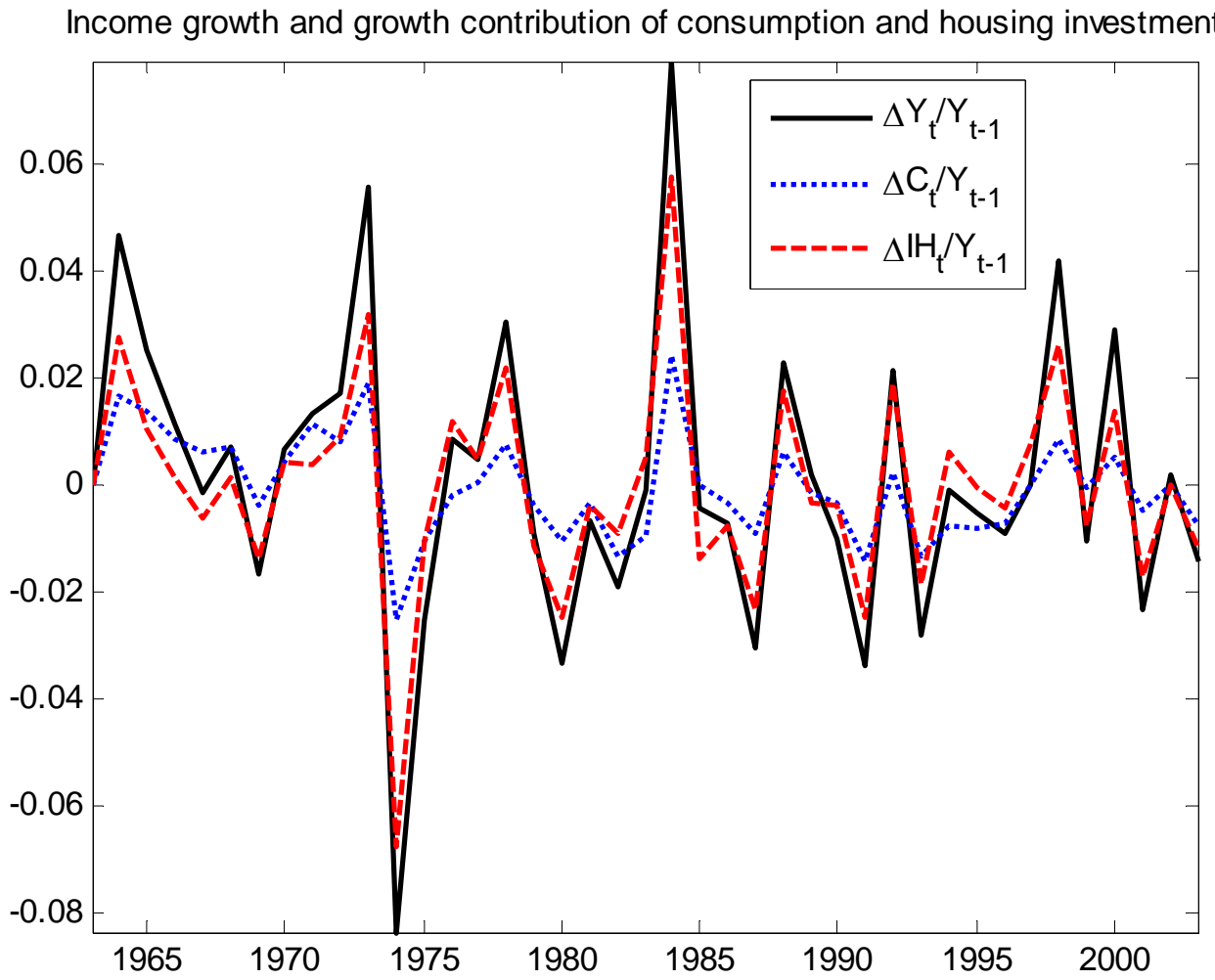


FIGURE 6: Comparison between the Model and the Data: Household Debt over Income

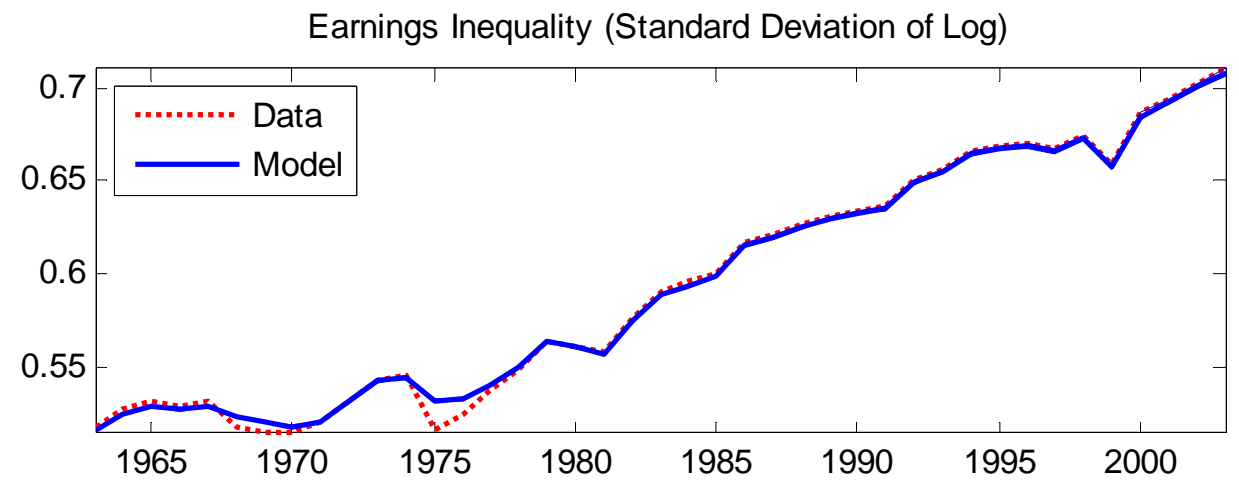

Household Debt over Income

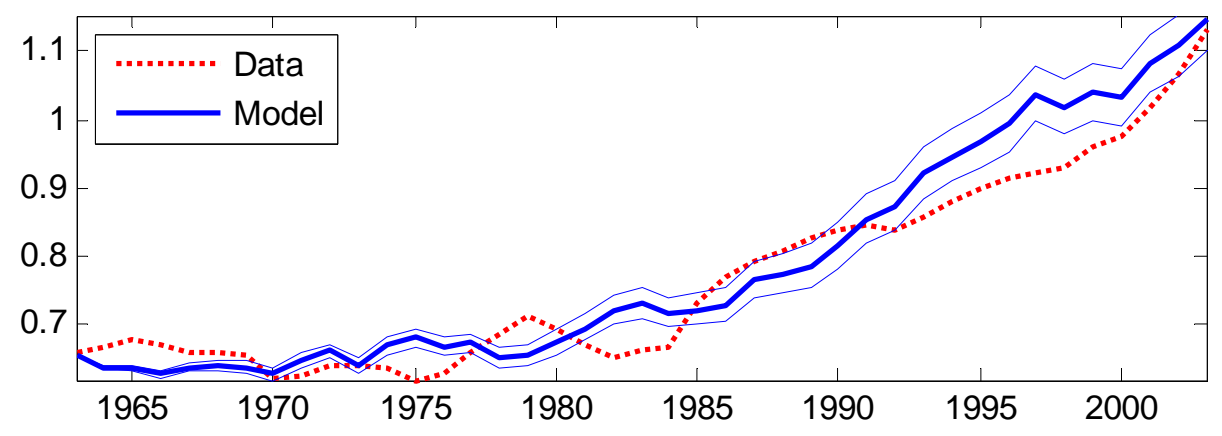

Note: The lighter, solid lines indicate $10^{\text {th }}$ and $90^{\text {th }}$ percentile for the model variable in the simulated data. 
FIGURE 7: Comparison between Model and Data: Household Debt Growth

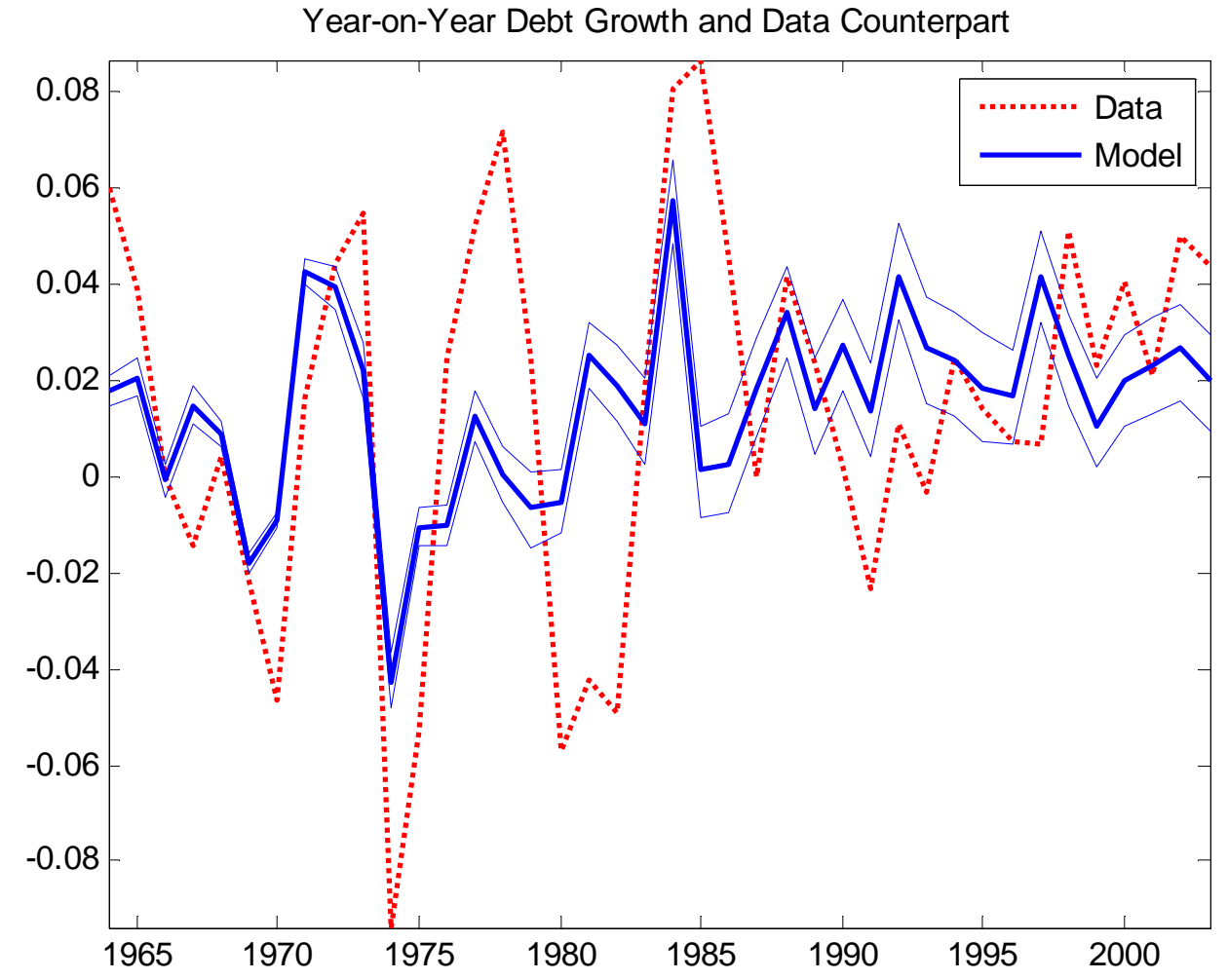

Note: The lighter, solid lines indicate $10^{\text {th }}$ and $90^{\text {th }}$ percentile for the model variable in the simulated data. 
FIGURE 8: Simulated Time Series for Income, Consumption and Wealth Inequality
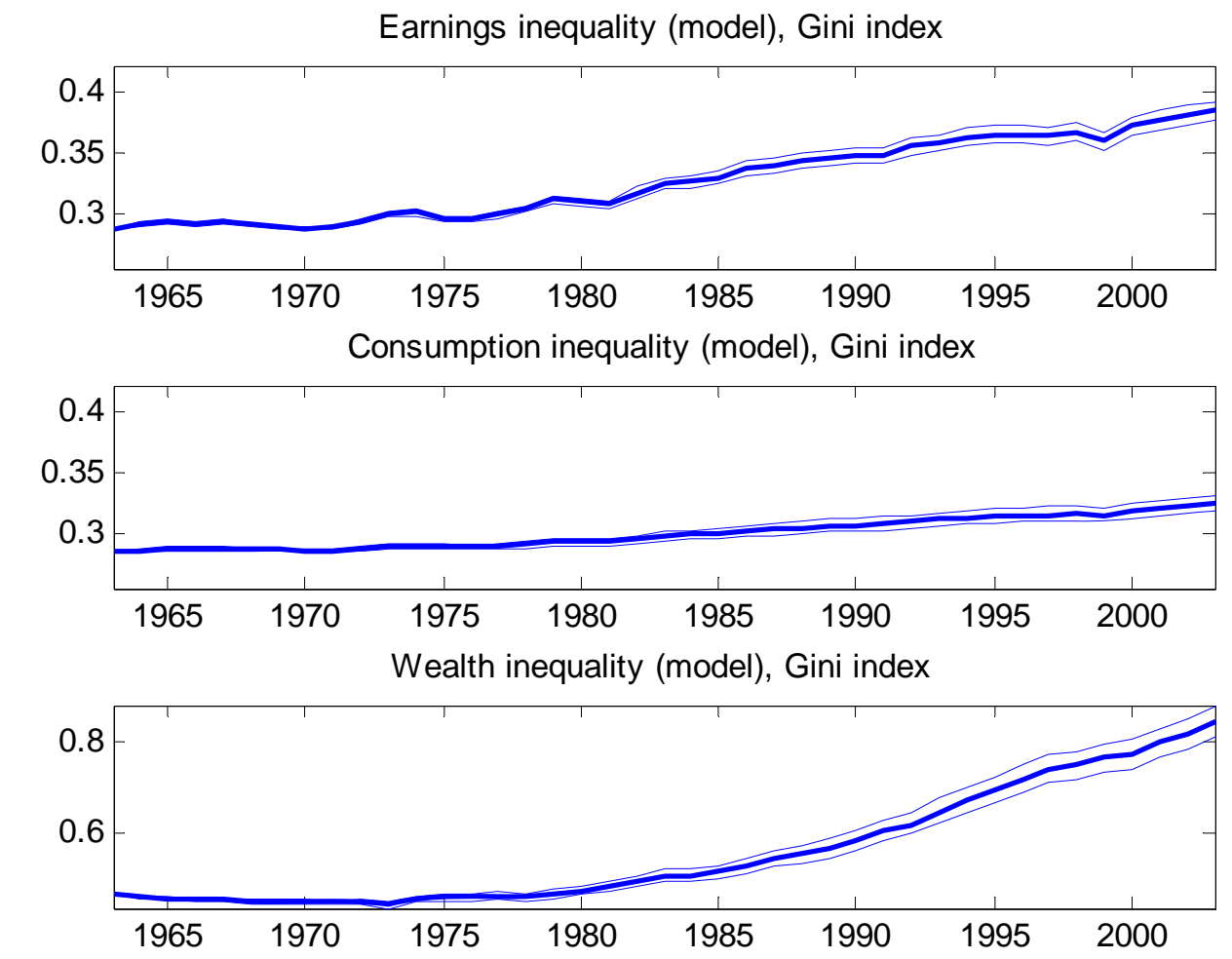

Note: The lighter, solid lines indicate $10^{\text {th }}$ and $90^{\text {th }}$ percentile for the model variable in the simulated data. 
FIGURE 9: Counterfactual Experiment: Simulated Time Series for Household Debt over Income

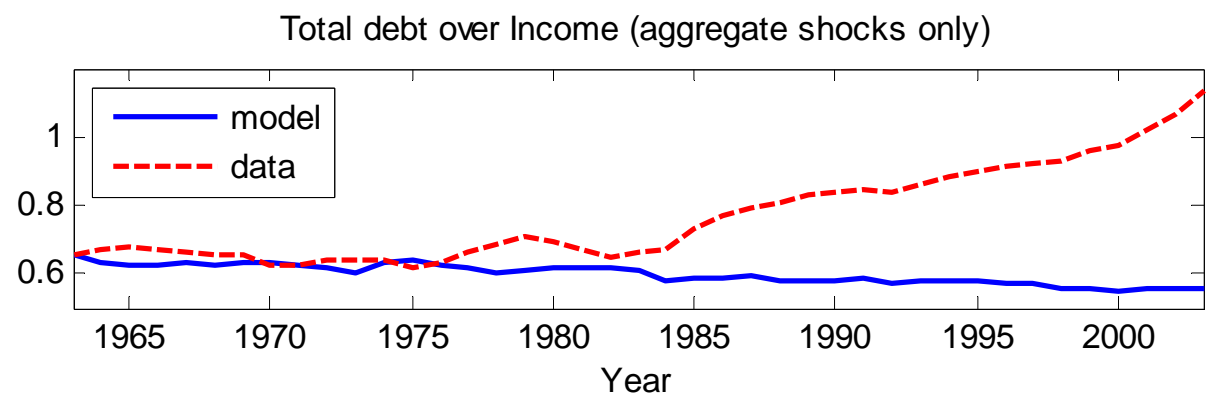

Total debt over Income (m shocks only)

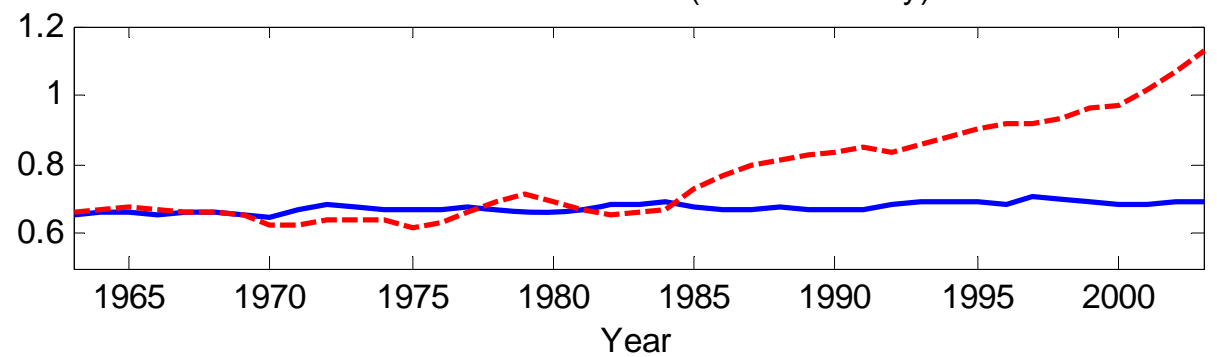

Total debt over Income (idiosyncratic shocks only)

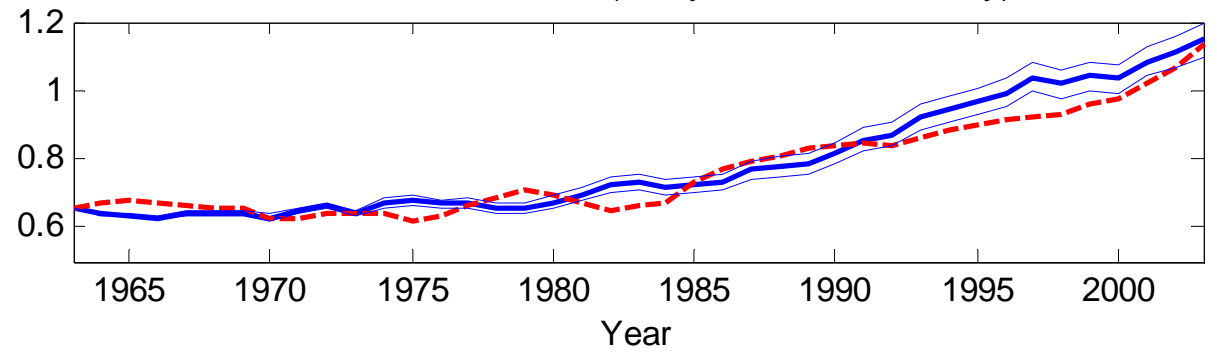


FIGURE 10: Counterfactual Experiment: Simulated Time Series for Change in Household Debt

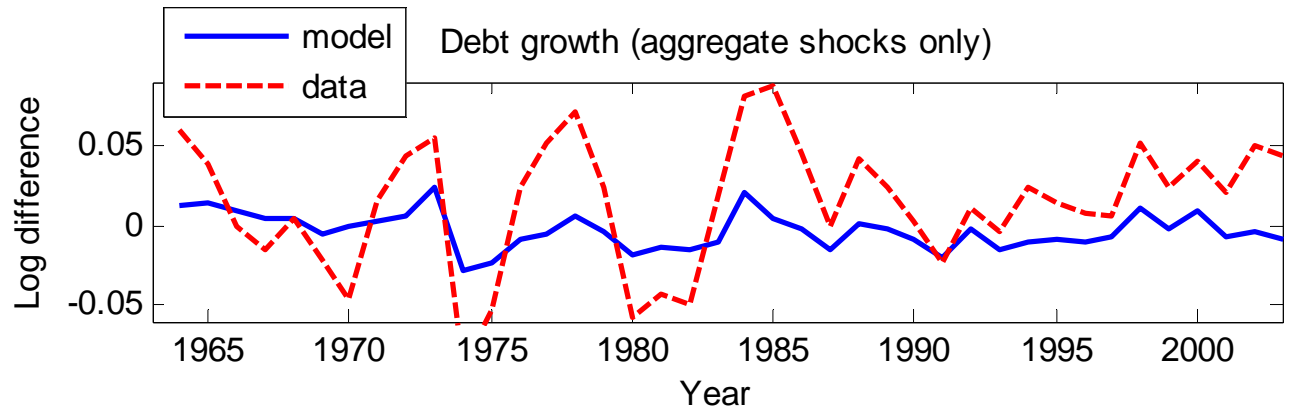

Debt growth (m shocks only)

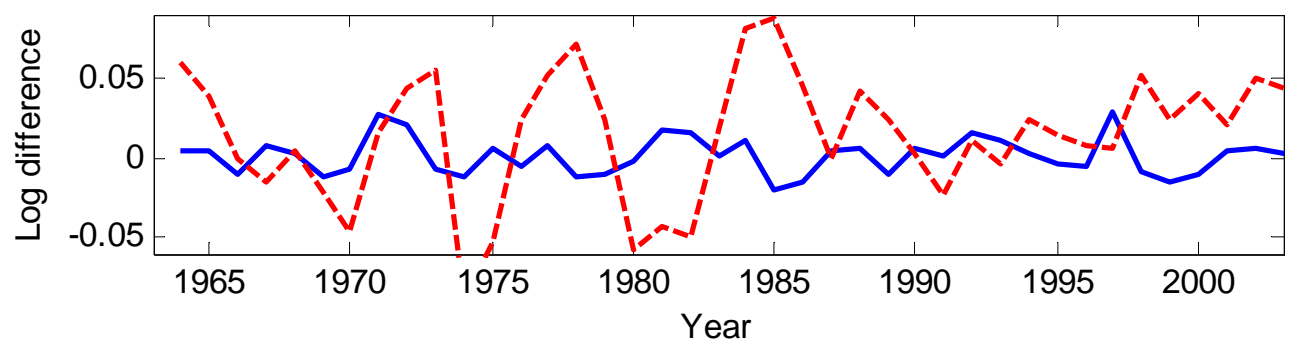

Debt growth (idiosyncratic shocks only)

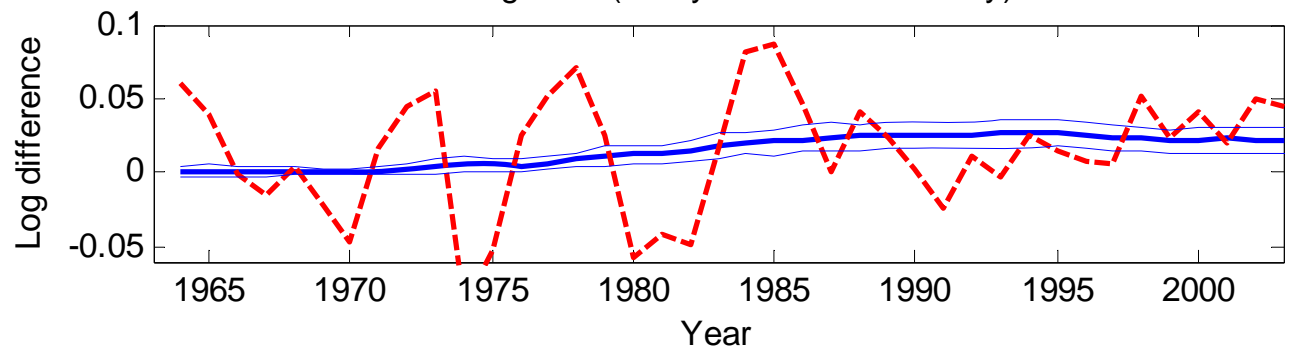

Note: Debt growth is defined as the change in total household debt scaled by total income. 
FIGURE 11: Policy Rules for the Non-Linear Model
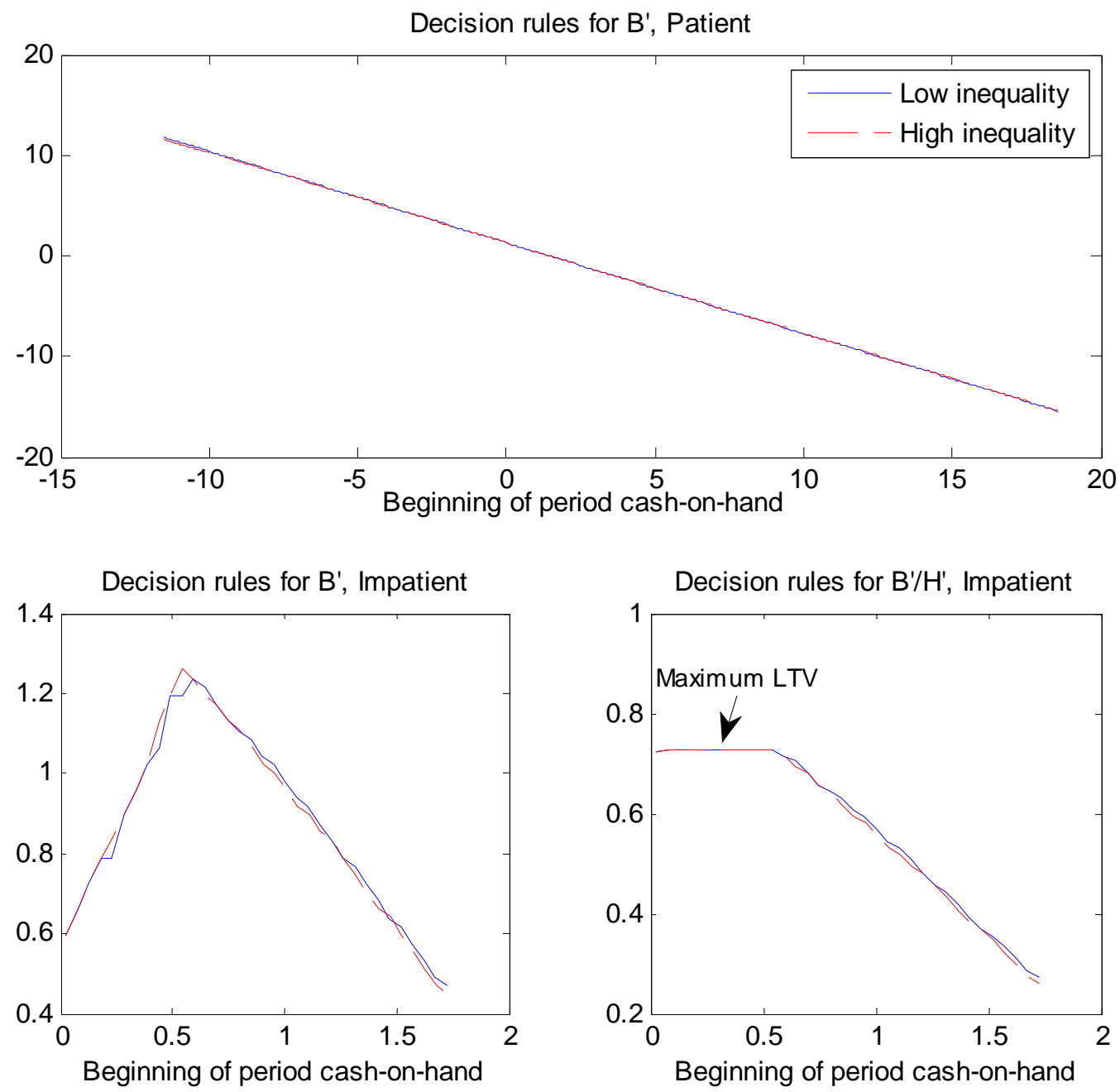

Note: The top panel plots the policy function for next period debt of a patient/unconstrained agent as a function of beginning of period "cash-on-hand" in the median income state. Cash-onhand is defined as beginning of period durables less debt repayment. The bottom panel plots the decision rules of an impatient/credit constrained agent: the left panel plots debt as a function of beginning of period "cash-on-hand"; the right panel plots the optimal ratio of borrowing over durables. 
FIGURE 12: Transitional Dynamics of the Non-Linear Model following an Increase in Earnings Volatility

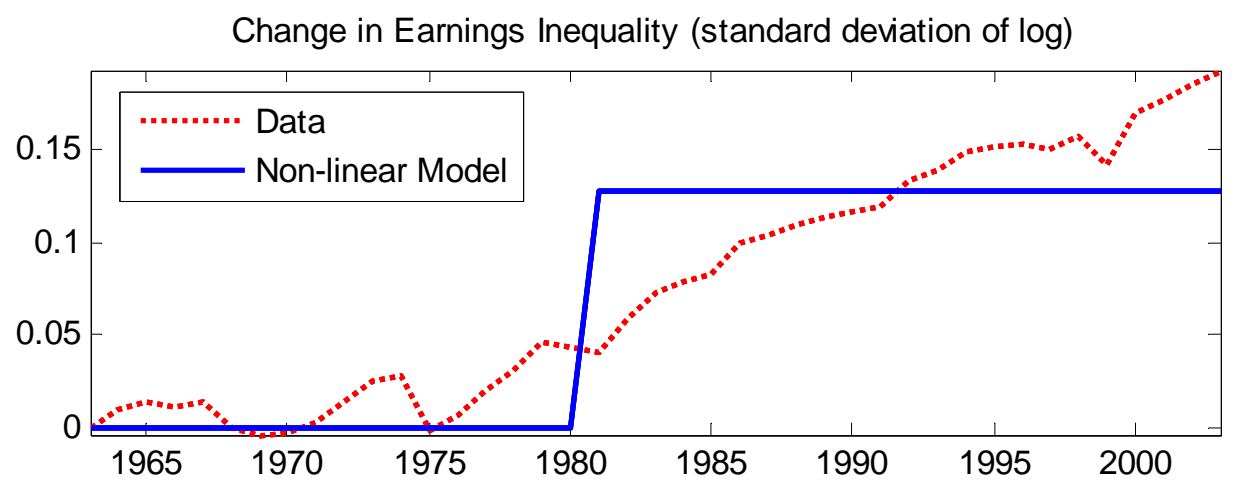

Household Debt over Income

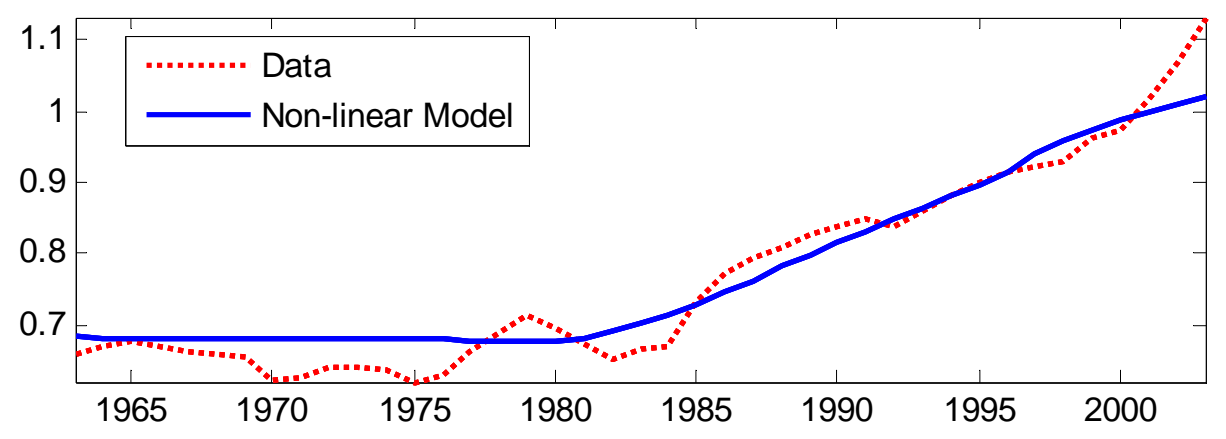

Note: The top panel plots the change in inequality relative to 1963 in the data and in the simulated experiment of the non-linear model, where inequality rises by 13 basis points. The bottom panel plots the data and the implied behavior of the debt to income ratio. 